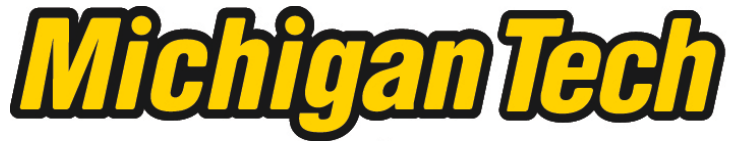 \\ Michigan Technological University Create the Future Digital Commons @ Michigan Tech
}

Dissertations, Master's Theses and Master's Reports - Open

Dissertations, Master's Theses and Master's

Reports

2012

\section{Great Lakes tributary phosphorus bioavailability}

Renn Sterling Lambert

Michigan Technological University

Follow this and additional works at: https://digitalcommons.mtu.edu/etds

Part of the Civil and Environmental Engineering Commons

Copyright 2012 Renn Sterling Lambert

\section{Recommended Citation}

Lambert, Renn Sterling, "Great Lakes tributary phosphorus bioavailability", Master's Thesis, Michigan Technological University, 2012.

https://doi.org/10.37099/mtu.dc.etds/250

Follow this and additional works at: https://digitalcommons.mtu.edu/etds

Part of the Civil and Environmental Engineering Commons 
GREAT LAKES TRIBUTARY PHOSPHORUS BIOAVAILABILITY

By

Renn Sterling Lambert

\begin{abstract}
A THESIS
Submitted in partial fulfillment of the requirements for the degree of MASTER OF SCIENCE

(Environmental Engineering)
\end{abstract}

MICHIGAN TECHNOLOGICAL UNIVERSITY

2012

(C) Renn Lambert 2012 
This thesis, "Great Lakes Tributary Phosphorus Bioavailability," is hereby approved in partial fulfillment of the requirements for the Degree of MASTER OF SCIENCE IN ENVRONMENTAL ENGINEERING.

Department of Civil and Environmental Engineering

Signatures:

Thesis Advisor

Dr. Martin Auer

Department Chair

Dr. David Hand

Date 
To my family: Karen, Jacqueline, and Bridget 


\section{Table of Contents}

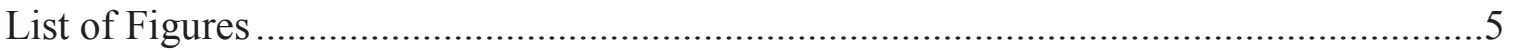

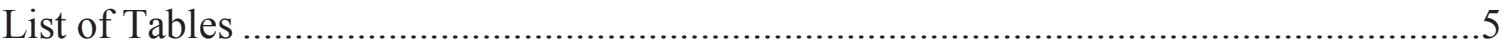

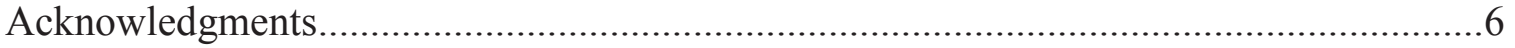

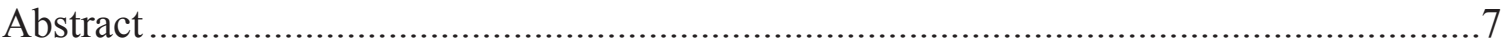

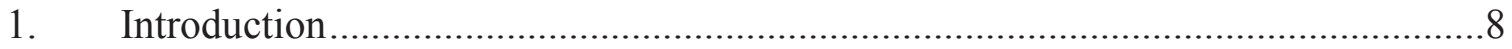

1.1 Assessing Phosphorus Bioavailability ………............................................. 9

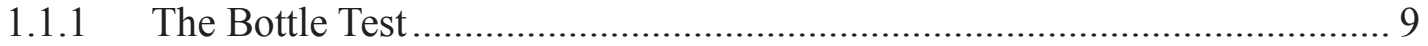

1.1.2 The Dual Culture Diffusion Apparatus ………………………………....... 10

1.1.3 Chemical Extraction.................................................................................... 11

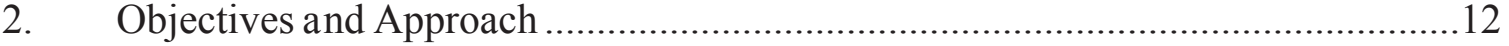

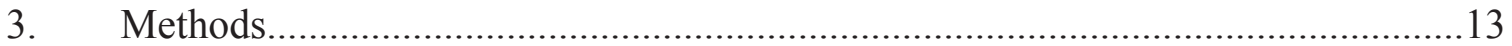

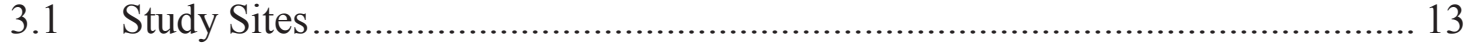

3.1.1 Site Characterization........................................................................... 13

3.1.2 Sample Collection and Processing ............................................................ 13

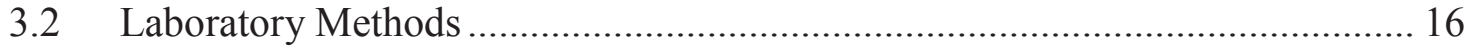

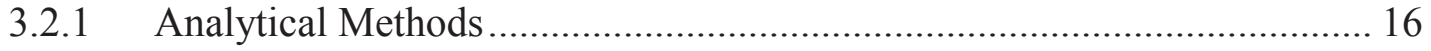

3.2.2 Soluble Phase - Bottle Test Assay ............................................................... 18

3.2.3 Particulate Phase - Dual Culture Diffusion Apparatus ............................... 18

3.2.4 Chemical Extraction........................................................................ 19

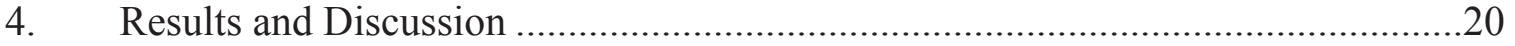

4.1 Assay Application and Repeatability …………………………………….... 20

4.1.1 Dissolved Phosphorus ............................................................................. 20

4.1.2 Particulate Phosphorus..................................................................... 22

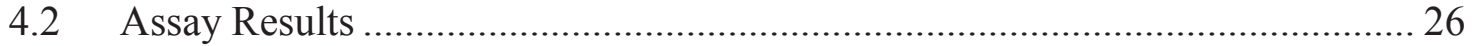

4.3 Alternative Methods for Determining Bioavailable P........................................ 30

4.3.1 $\mathrm{Fe} / \mathrm{Al}-\mathrm{P}$ : the $\mathrm{NaOH}$ extractable fraction …………..................................... 30

4.3.2 Correlating PP bioavailability, richness and chemical fractions ................ 33

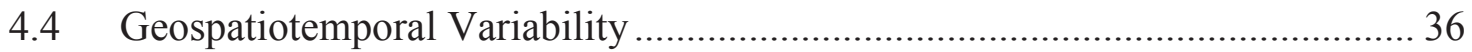

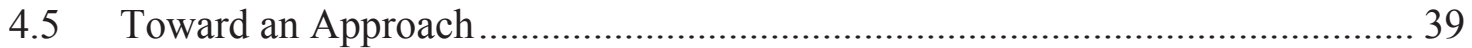

4.6 A Proposed Monitoring Program ................................................................ 40

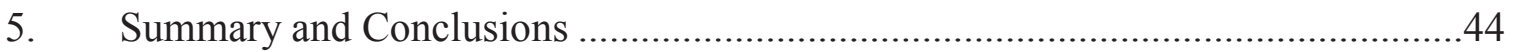

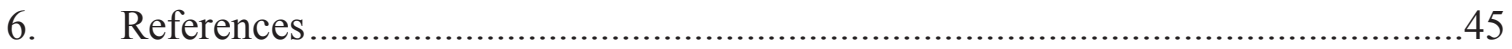




\section{List of Figures}

Figure 3.1 Land use off all watersheds (Fry et al., 2011)......................................... 14

Figure 3.2 Hydrographs from all of the rivers sampled. ........................................... 15

Figure 3.3. Break down of all phosphorus fractions ................................................... 17

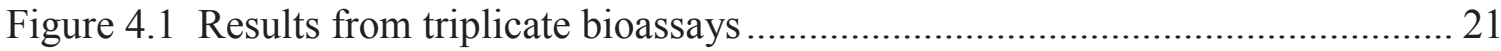

Figure 4.2 Bioavailability of the Maumee River. .............................................................. 24

Figure 4.3 DCDA bioavailable P, versus the change in P richness ............................. 25

Figure 4.4 The DOP concentrations plotted with the bioavailable DOP concentrations.. 29

Figure 4.5 Bioavailability measured by DCDA and $\mathrm{NaOH}$ extractable P methods ........ 31

Figure 4.6 Relationship between sample P richness and DCDA bioavailable P............. 34

Figure 4.7 Regressions of DCDA bioavailability and fractions ................................... 37

Figure 4.8 The fraction bioavailable $\left(f_{\text {bio }}\right)$ of all samples ........................................... 41

Figure 4.9 Contributions of SRP, DOP and PP to TP and bioavailable phosphorus....... 42

List of Tables

Table 4.1 Tributary $\mathrm{P}$ concentrations and results from all bioassays and fractionations.. 27 


\section{Acknowledgments}

I would like to thank the Upstate Fresh Water Institute for funding my research, collecting and sending samples, collaborating with me on publications, and opening up their facilities for some work related to my research. I would like to recognize the Scholarships Science, Technology, Engineering and Mathematics (S-STEM) program at Michigan Tech for funding. I appreciate Dr. Martin Auer for his many hours of editing, troubleshooting, and his patience and perseverance in teaching me. He was always pushing me, and he let me know when he expected more. He pushed me beyond what I thought my limits were, and this helped me grow both professionally and academically. I would also like to express gratitude to my committee: Dr. Amy Marcarelli and Dr. Alex Mayer, for their help, encouragement, and their review of my work.

Recognition is due to all those who helped with the intense lab work involved in collecting bioassay data: Phillip DePetro, Natalie Minott, Jennifer Fuller, Erica Jones, and Konrad Roznik. In addition, I am grateful to Aaron Dayton for his encouragement and help.

I express love and gratitude to my wife and children: Karen, Jacqueline, and Bridget. They were patience and understanding in all the long hours I was gone from home while a graduate student. They encouraged and helped me, and facilitated a balance between work and recreation, and most of all they helped me become a better person and hopefully a better dad.

I am also grateful to: my church leader, President Raymond Shaw; my parents, Karson and Lenna Lambert; and my mother and father-in-law, Steven and Patricia Hunt who took time to encourage me while I was completing my degree. Lastly, but most importantly I would like to thank my Heavenly Father who gives me all of life's blessings. 


\begin{abstract}
Information on phosphorus bioavailability can provide water quality managers with the support required to target point source and watershed loads contributing most significantly to water quality conditions. This study presents results from a limited sampling program focusing on the five largest sources of total phosphorus to the U.S. waters of the Great Lakes. The work provides validation of the utility of a bioavailability-based approach, confirming that the method is robust and repeatable. Chemical surrogates for bioavailability were shown to hold promise, however further research is needed to address site-to-site and seasonal variability before a universal relationship can be accepted. Recent changes in the relative contribution of $\mathrm{P}$ constituents to the total phosphorus analyte and differences in their bioavailability suggest that loading estimates of bioavailable $\mathrm{P}$ will need to address all three components (SRP, DOP and PP). A bioavailability approach, taking advantage of chemical surrogate methodologies is recommended as a means of guiding P management in the Great Lakes.
\end{abstract}




\section{Introduction}

Under the Great Lakes Water Quality Agreement of 1978, the International Joint Commission implemented a phosphorus management plan (IJC, 1978). Loading reductions achieved through the Agreement led to changes in trophic state (DePinto et al., 2006), including the controversial oligotrophication of Lakes Huron, Michigan and Ontario (Evans et al., 2011). The eutrophication goals set under the Great Lakes Water Quality Agreement have now been met in the offshore waters of all the Great Lakes; except, Lake Erie where nuisance levels of Microcystis have been documented in Maumee Bay near the mouth of the Maumee River and across the western basin of Lake

Erie (Bridgeman et al., 2011). These objectives have not, however, been adequately addressed for impairment of nearshore waters. This failure is, at least in part, related to the invasion of zebra mussels, which have dramatically changed nutrient dynamics and the ecological makeup of the Great Lakes (e.g. the nearshore phosphorus shunt; Hecky et al., 2004). The filtering process of mussels results in increased water clarity and serves to convert particulate phosphorus to more bioavailable dissolved phosphorus. These activities create ideal conditions for benthic algae such as Cladophora, which has returned to nuisance levels not observed since the 1980s (Auer et al., 2010). These remaining eutrophication issues have lead to recommendations that the Great Lakes phosphorus management program be revaluated. According to Evans et al. (2011), phosphorus loading studies should be performed on a tributary by tributary basis considering the water quality objectives and lost beneficial uses of the adjacent nearshore. 
Phosphorus loading management involves the control of both point (industrial and municipal wastewater) and non-point sources (principally agriculture). Loads include contributions of three forms of phosphorus: soluble reactive P (SRP), dissolved organic-P (DOP), and particulate $\mathrm{P}(\mathrm{PP})$. These forms differ in their relative contribution to total $\mathrm{P}$ (TP) loads and in their bioavailability. The SRP, DOP and PP characteristics are easily evaluated through traditional monitoring programs and the bioavailability may be quantified with algal and chemical assay techniques (Auer et al., 1998; DePinto, 1982; DePinto et al., 1981; Effler et al., 2012; Effler et al., 2002; Ekholm, 1994; Ekholm et al., 2007; Ekholm and Krogerus, 1998; Ekholm and Krogerus, 2003; Ekholm et al., 2009; Miller et al., 1978; Uusitalo and Ekholm, 2003; Young et al., 1982; Young et al., 1985). These data can provide water quality managers with the support required to target watersheds with the largest bioavailable phosphorus loads. While this approach has been applied historically (DePinto et al., 1981), phosphorus bioavailability in Great Lakes tributaries have not been characterized in over 30 years. Considering the current state of the Great Lakes, it is appropriate to revisit this issue.

\subsection{Assessing Phosphorus Bioavailability}

A variety of approaches have been used to define the bioavailability of the various phosphorus fractions. Here, the methods selected for use in our study are described and their applicability to each P fraction is identified.

\subsubsection{The Bottle Test}

The Bottle Test is an algal bioassay technique that was developed by Miller et al. (1978) and widely applied for evaluating agricultural runoff and river sediments 
(Bradford and Peters 1987; Dorich et al. 1980; 1985; Ellis and Stanford 1988; Ellison and Brett 2006; Engle and Sarnelle 1990; Fabre et al. 1996; Miller et al. 1978; Qotbi et al. 1996; Robinson et al. 1994; Sharpley et al. 1991; Sharpley 1993).

A modification of the bottle test protocol of Miller et al. (1978) may be applied in determining the bioavailability of dissolved phosphorus (i.e. SRP and DOP). A filtered $(0.45 \mu \mathrm{m})$ sample is placed in a bottle with P-starved algae and the reduction in SRP and DOP is measured over time as they are taken up by the algae. The assay continues until the dissolved $\mathrm{P}$ is depleted $(100 \%$ bioavailable) or the concentration reaches an asymptote (partial bioavailability).

\subsubsection{The Dual Culture Diffusion Apparatus}

The Dual Culture Diffusion Apparatus (DCDA) consists of two chambers separated by a black, $0.45 \mu \mathrm{m}$ membrane. One chamber holds the solids sample (slurry of particulate matter) to be assayed and the other P-starved algae. Phosphorus is released from particles in the solids sample, diffuses across the membrane and is taken up by the algae. Bioavailable $\mathrm{P}$ is quantified as the cumulative $\mathrm{P}$ uptake over the course of the assay and expressed as a percentage of the total phosphorus added to the apparatus.

The DCDA method was developed by (DePinto 1982) and applied in assessing the bioavailability of phosphorus in Great Lakes tributaries and wastewater treatment plant effluents (DePinto et al. 1981; Young et al. 1982; Young et al. 1985). Subsequently, the technique was applied to a variety of sources including paper mill effluent, river waters, and wastewater treatment plant effluent (Ekholm 1994; Ekholm and Krogerus 1998; Ekholm and Krogerus 2003; Ekholm et al. 2007; Ekholm et al. 2009). 
Bioavailability determined in this fashion should be (and is) the primary standard for assessing the eutrophication potential of nutrient sources, as it utilizes algae directly. However, algal bioassays are labor intensive and difficult to manage (Robinson et al. 1994). A simpler method would facilitate determination of bioavailability if it were shown to yield results comparable to that of the algal assay.

\subsubsection{Chemical Extraction}

Chemical methods (e.g. sequential extraction) have also been applied in assessing P bioavailability (Dorich et al. 1980; Fabre et al. 1996; Hodson et al. 2004; Mayer et al. 1991; Sharpley et al. 1991; Zhou et al. 2001). DePinto et al. (1981) and Young et al. (1985) demonstrated that the $\mathrm{NaOH}$ extractable fraction approximated the amount of $\mathrm{P}$ determined to be available using algal bioassays. However, this relationship does not hold true for all water sources (Boström et al. 1988). For example, Young et al. (1982) found that algal and chemical assays were poorly correlated in application to wastewater plant effluents. Here, a four fraction sequential extraction procedure is applied and the correlation of those fractions with bioavailable $\mathrm{P}$ determined through algal assays examined. 


\section{Objectives and Approach}

The goal of this research is to examine the bioavailability of soluble and particulate phosphorus entering the Great Lakes from tributaries representing the five largest loads to United States waters (Personal Communication, Dr. David Dolan). The objectives identified in order to obtain this goal were as follows:

1. Assess the repeatability of algal bioassay methods

2. Quantify the utility of chemical surrogates for determining PP bioavailability

3. Determine the contributions of PP, DOP and SRP to TP and bioavailable P loads

4. Propose a monitoring program which would implement the estimation of bioavailability at major tributaries

The approach taken to obtain these objectives included the measurement of the bioavailability of dissolved and particulate phosphorus using algal bioassay and chemical fractionation methods. Assay results quantify the fraction of the total phosphorus analyte that is bioavailable and the contribution of soluble reactive $\mathrm{P}$, dissolved organic-P and particulate $\mathrm{P}$ to that fraction. 


\section{Methods}

\subsection{Study Sites}

\subsubsection{Site Characterization}

Four of the five tributaries have a largely agricultural watershed, and the Cuyahoga River is dominated by an urban (41\%) and undeveloped (43\%) watershed (Figure 3.1). The Fox River has an upper (90\% of land area) and lower watershed that is separated by Lake Winnebago. Therefore, the lower stretch is from the outfall of the lake which is high in particulate organic matter associated with algae and low in inorganic particulate matter (such as clays that wash off of row crop fields). A large portion of the Fox River watershed is undeveloped (50\%). The outfall of Lake Winnebago is controlled and there are no flood peaks on the hydrograph. The other rivers are free flowing, and it appears that 2011 was a wetter year than 2010 because the flood peaks were larger and more frequent in 2011 in all of the watersheds (Figure 3.2). The summer of 2010 was dry and there was more rain in the summer of 2011. It will be shown that flow patterns in the rivers can affect phosphorus bioavailability.

\subsubsection{Sample Collection and Processing}

Samples were collected (40 L grab) at the following locations: the Maumee River at Toledo, Ohio (11/20/2010), the Fox River at Green Bay, Wisconsin (11/28/2010 and 10/26/2011), the Saginaw River at Bay City, Michigan (11/20/2010), the Sandusky River at Fremont, Ohio (11/20/2010 and 10/26/2011) and the Cuyahoga River at Cleveland, Ohio $(11 / 20 / 2010$ and $7 / 11 / 2011$; Figure 3.2 , characterization of the flows during sampling). Samples were transported to Michigan Technological University and stored 

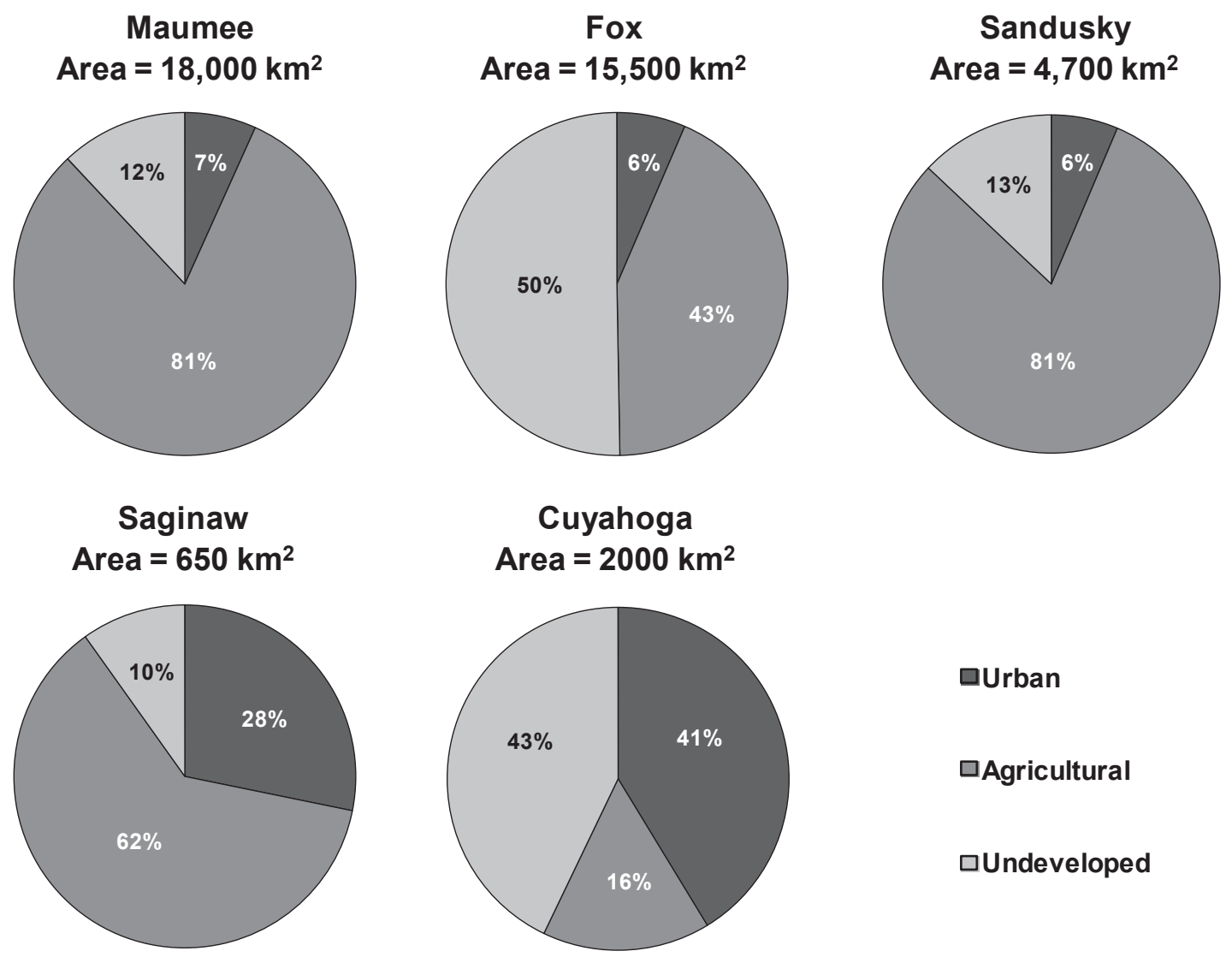

Figure 3.1 Land use off all watersheds (Fry et al., 2011). 


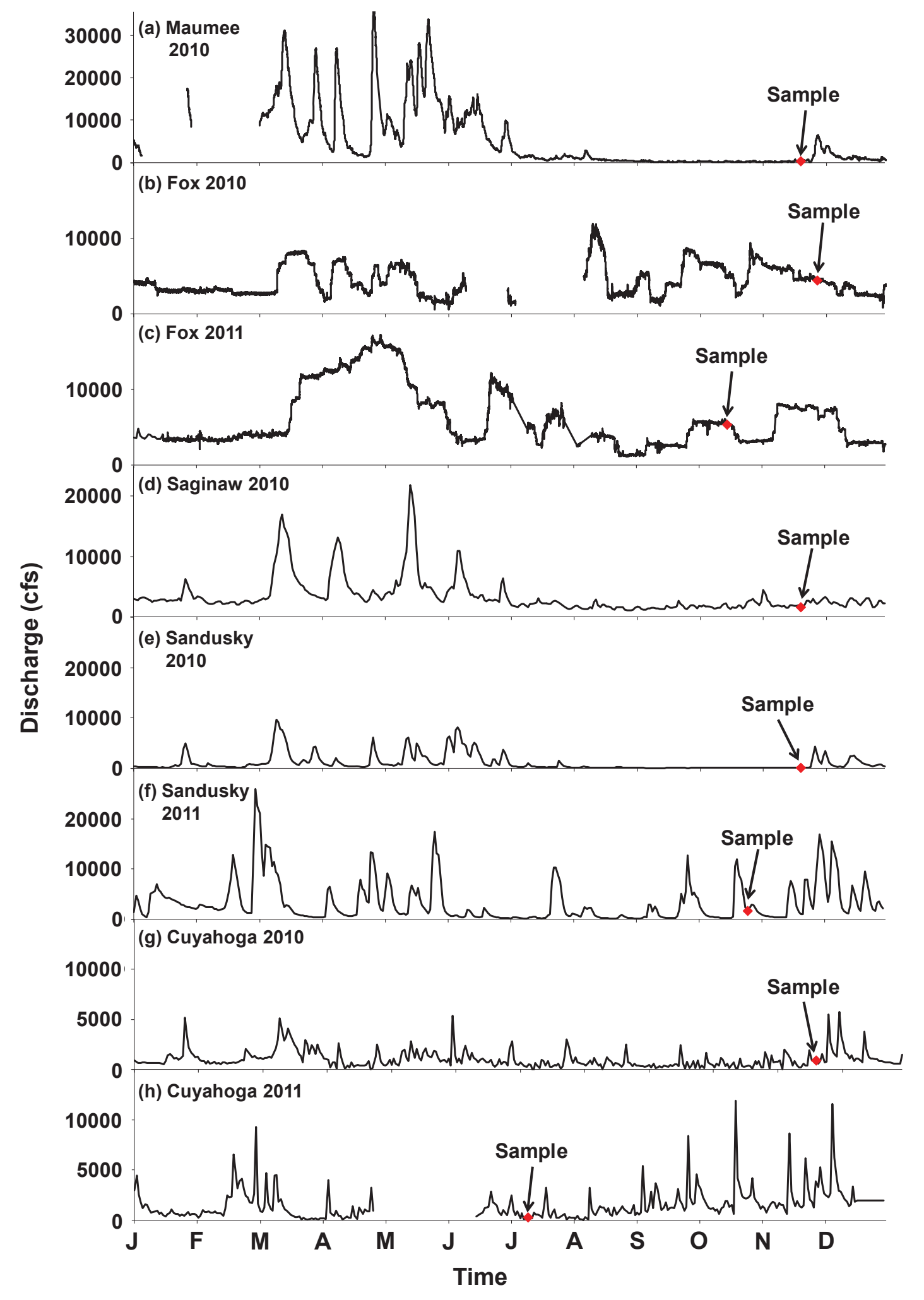

Figure 3.2 Yearly hydrographs from the rivers sampled. The time of sampling is noted on the graph. 
in the dark at $4{ }^{\circ} \mathrm{C}$ until processed, usually within 2-3 days of collection. Each $40-\mathrm{L}$ sample was passed under positive pressure through a $142 \mathrm{~mm}, 0.45 \mu \mathrm{m}$ cellulose acetate filter (GE Osmonics Labstore). Filtrate was collected and refrigerated at $4^{\circ} \mathrm{C}$. Particulate matter was scraped off of the filters and placed in glass bottles containing a small amount of filtrate to create a slurry which was then frozen $\left(-20^{\circ} \mathrm{C}\right)$. Particulate samples were split into aliquots supporting three analyses: phosphorus richness (mass P per mass dry solids), particulate phase bioassays, and particulate phase chemical fractionation assays.

\subsection{Laboratory Methods}

\subsubsection{Analytical Methods}

SRP was measured spectrophotometrically by the ascorbic acid method (APHA, 2005). PP and TDP samples were digested by the persulfate method (APHA, 2005), converting the phosphorus to SRP. Dissolved organic phosphorus (DOP) is defined operationally as TDP minus SRP (Figure 3.3).

P-richness was determined by placing an aliquot of slurry on a $47 \mathrm{~mm}, 0.4 \mu \mathrm{m}$ polycarbonate membrane filter (Whatman, Florham Park, New Jersey) and excess liquid was removed by vacuum filtration. The filter was dried at $103{ }^{\circ} \mathrm{C}$, reweighed and placed in an Erlenmeyer flask to be processed for PP determination yielding the mass of phosphorus $(\mu \mathrm{gP})$ present in the sample. The dried filter weight minus the tared filter weight yields the mass of dry solids (gDW), and from this P-richness $\left(\mu \mathrm{gP} \cdot \mathrm{gDW}^{-1}\right)$ may be calculated. 


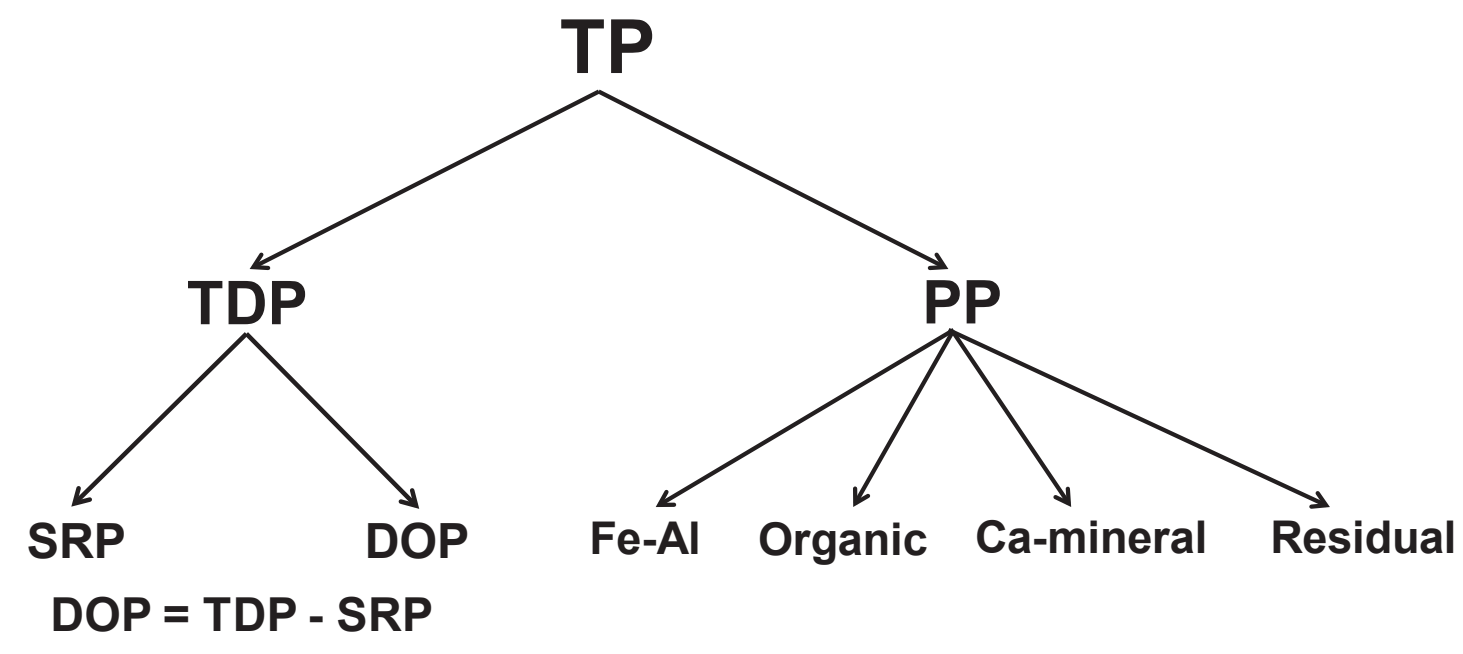

Figure 3.3. Break down of all phosphorus fractions, including chemical fractionations of Particulate Phosphorus. 


\subsubsection{Soluble Phase - Bottle Test Assay}

Soluble phase assays were conducted using a modification of the bottle test procedure of Miller et al. (1978). The initial SRP and DOP content of filtered water samples were determined and 2-3 L of sample was placed into a 4-L Erlenmeyer flask. Pstarved algae (Selenastrum capricornutum) were added to the flask and the sample was incubated in the light $\left(\mathrm{PAR}=600 \mu \mathrm{E} \cdot \mathrm{m}^{-2} \cdot \mathrm{s}^{-1}, 24\right.$ hour light $)$ at $20^{\circ} \mathrm{C}$. SRP and DOP were measured at intervals of 1-7 days (more frequent at the beginning) and the incubation was continued for 30 days. The amount of SRP and DOP taken up by the algae divided by the initial concentration and expressed as a percent yields the bioavailability.

\subsubsection{Particulate Phase - Dual Culture Diffusion Apparatus}

The Dual Culture Diffusion Apparatus (DCDA) is a device developed by DePinto (1982) which can be used to perform algal bioassays. The DCDA consists of two chambers bolted together $(1.6 \mathrm{~L}$ total) with a $90 \mathrm{~mm}, 0.45 \mu \mathrm{m}$ black mixed cellulose ester (MCE) filter placed between them. One chamber is dark and contains an aliquot of particulate sample diluted with P-free algal growth medium (described in APHA, 2005). The other chamber is exposed to light $\left(\mathrm{PAR}=600 \mu \mathrm{E} \cdot \mathrm{m}^{-2} \cdot \mathrm{s}^{-1}, 24\right.$ hour light $)$ and contains P-free algal growth medium inoculated with P-starved algae (Selenastrum capricornutum).

The initial PP concentration in the particulate and algal chambers is measured and the system is incubated for 30 days at $20{ }^{\circ} \mathrm{C}$ with continuous stirring. Algae are harvested every three days, and replaced with fresh, P-starved algae. The PP concentration of the algae removed from and added to the DCDA is measured at each 
harvest. The change in the phosphorus content of the algae over each incubation interval $\left(\mathrm{C}_{\mathrm{t}=3}-\mathrm{C}_{\mathrm{t}=0}\right)$ is calculated and added to that for previous harvests to yield the cumulative algal $\mathrm{P}$ uptake. As the assay proceeds and the bioavailable $\mathrm{P}$ pool is depleted, algal uptake ceases. The cumulative uptake represents the bioavailable $\mathrm{P}$ and is expressed as a fraction $\left(f_{\text {bio }}\right)$ of the total phosphorus content of the sediment sample added.

\subsubsection{Chemical Extraction}

Chemical extraction techniques have been used to develop a surrogate representation of PP bioavailability. A particulate $\mathrm{P}$ sample is subjected to a two-step sequential extraction procedure (Penn et al., 1995; Penn and Auer, 1997) which yields four fractions: the Fe/Al-P fraction (loosely bound, sorbed P; also termed the $\mathrm{NaOH}$ extractable fraction), the organic-P fraction (biogenic polyphosphates and easily mineralized organic-P), the Ca-mineral fraction (apatite), and the residual fraction (refractory P; Figure 3.3). These four fractions are then summed to yield the total phosphorus content of the sample.

In the first extraction, $50 \mathrm{~mL}$ of $0.1 \mathrm{~N} \mathrm{NaOH}$ are added to $\sim 50 \mathrm{mgDW}$ of sediment and the resulting slurry is shaken for 17 hours. The slurry is then centrifuged and the supernatant is neutralized to $\mathrm{pH} 8$ before being split into two aliquots: one to be analyzed for SRP (representing the Fe/Al-P fraction) and one to be analyzed for DOP (representing the organic-P fraction). The sequential extraction continues by adding $50 \mathrm{~mL}$ of $0.5 \mathrm{~N}$ $\mathrm{HCl}$ to the material remaining. That slurry is shaken for 24 hours and centrifuged. The supernatant is neutralized to $\mathrm{pH} 8$ and analyzed for SRP (representing the Ca-mineral P fraction). The remaining solids are analyzed for PP and represent the residual P fraction. 


\section{Results and Discussion}

\subsection{Assay Application and Repeatability}

Analytical methods must be repeatable if the results are to be used for management purposes. Triplicate analyses were performed on one sample collected from the Maumee River on November 20, 2010. The repeatability of the three assay methods (DCDA, PP; chemical fractionation, PP; bottle test, DOP and SRP) were assessed from this sample.

\subsubsection{Dissolved Phosphorus}

$\underline{\mathrm{SRP}}$ - it is widely accepted that soluble reactive phosphorus is readily available to algae (Boström et al., 1988; Young et al., 1982). In triplicate bottle test analyses of the Maumee River sample, SRP was completely and repeatably depleted after 4 days of incubation (Figure 4.1a), supporting conclusions in the literature that SRP is highly available.

$\underline{\text { DOP }}$ - the bioavailability status of DOP (also termed dissolved un-reactive P) is less clear. In a review of P bioavailability Persson (2001) concluded that the bioavailability of DOP is close to zero; however, Boström et al. (1988) reported a large range on DOP bioavailability (0 to $100 \%$ ) in a similar review. The latter position is consistent with the findings of Ekholm and Krogerus (2003) who measured DOP availability in runoff from fields and forests and discharges from rivers of varying drainage basin size and reported that the DOP was $0-55 \%$ bioavailable. Auer et al. (1998) determined through algal bioassays that DOP in the major tributary to Cannonsville Reservoir, New York was 100\% bioavailable. Connors et al. (1996) 
(a) Soluble Reactive Phosphorus

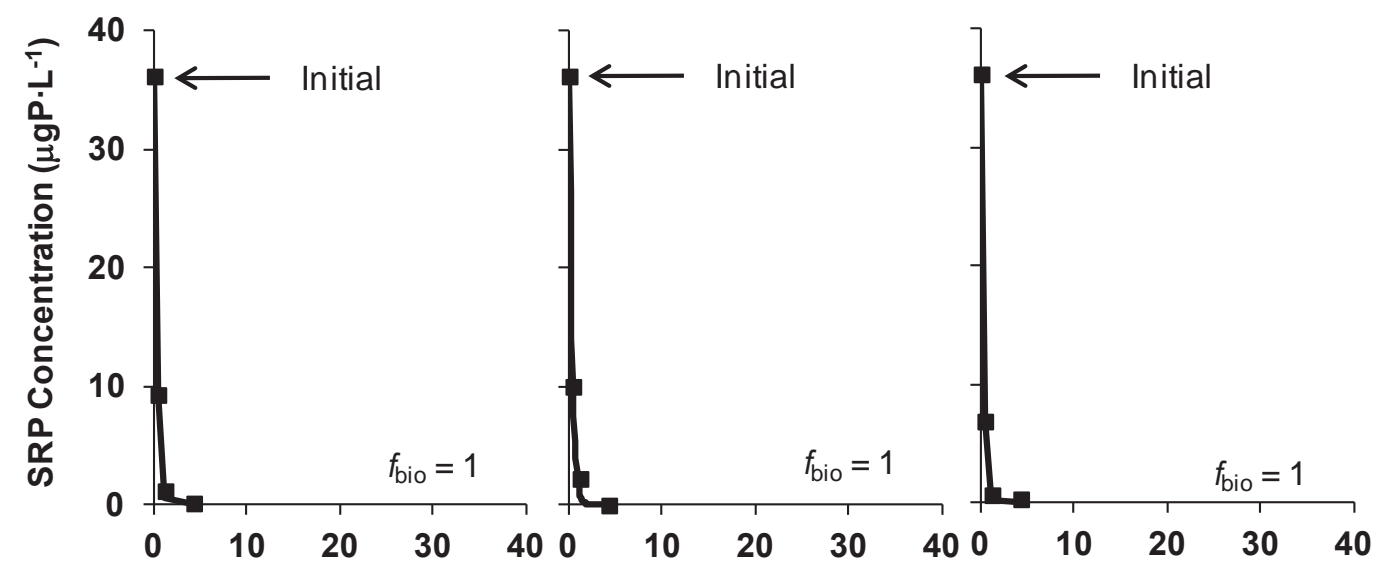

(b) Dissolved Organic Phosphorus

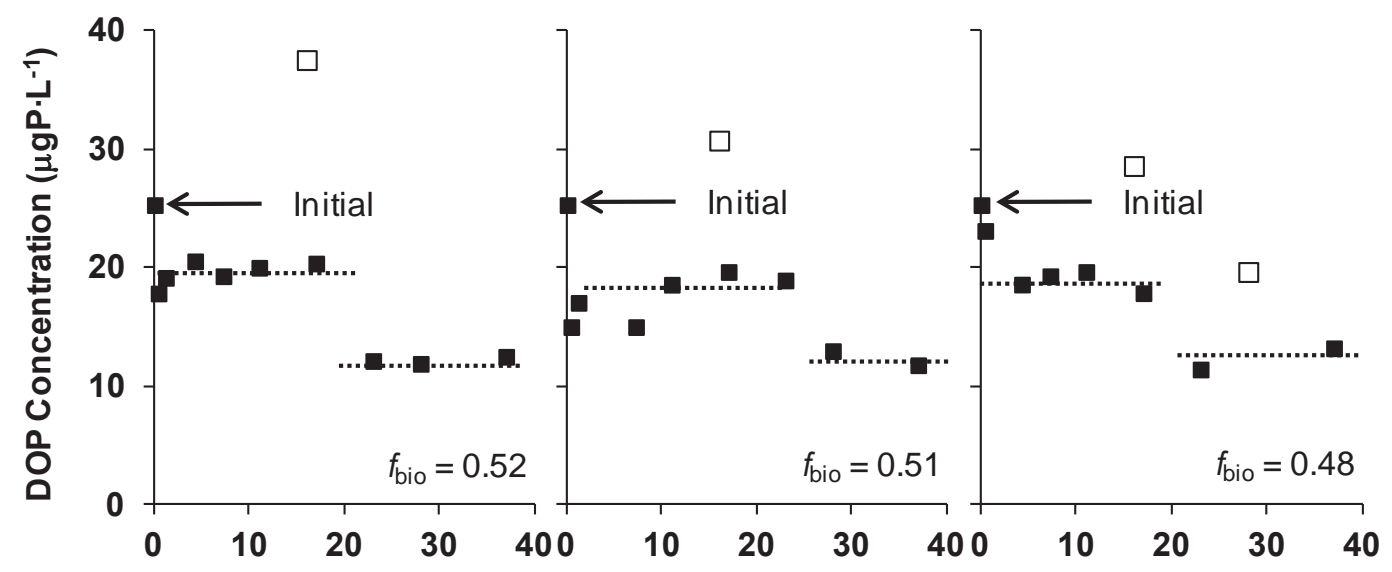

(c) Particulate Phosphorus

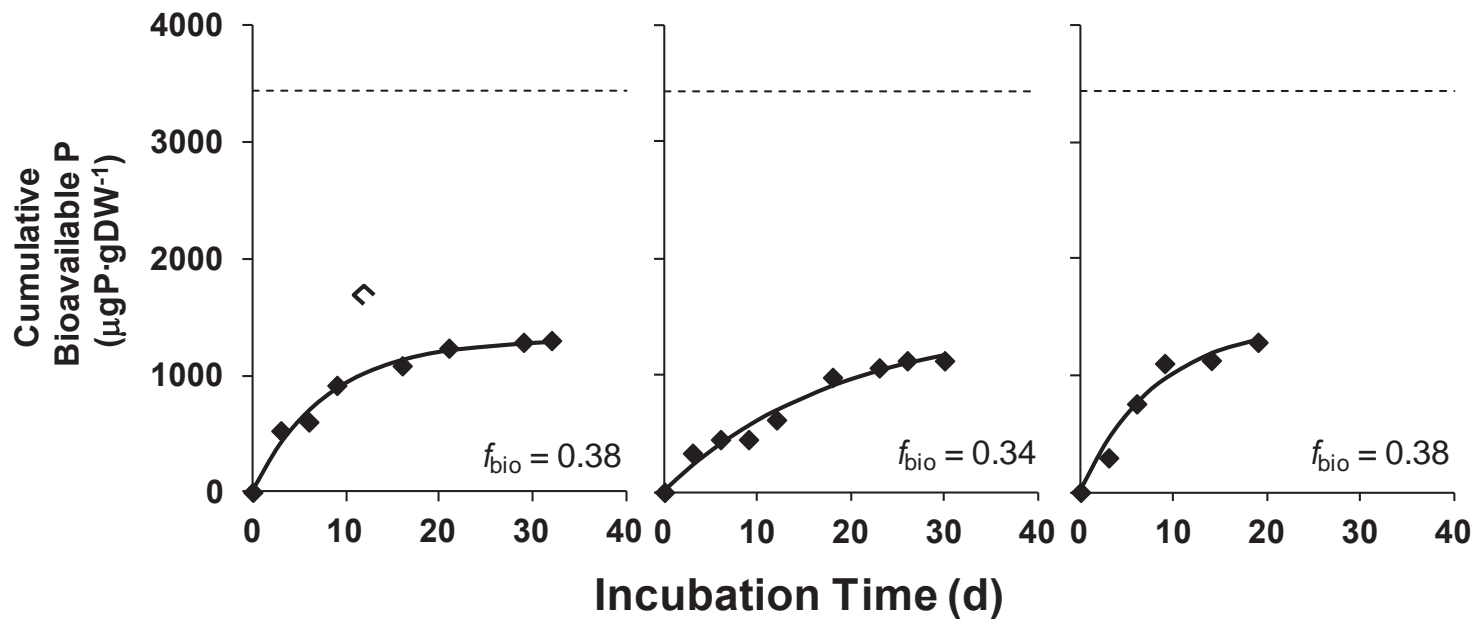

Figure 4.1 Results from triplicate bioassays conducted on a sample from the Maumee River collected on 11/20/2010: (a) bottle test SRP assays, (b) bottle test DOP assays and (c) DCDA PP assays. (hollow points were outliers) 
observed DOP concentrations in Onondaga Lake decline from spring to early summer, reaching an asymptote assumed to represent refractory DOP. In his review, Persson (2001) cites studies that indicate that DOP in sewage effluent is more bioavailable than that in tributaries. Ekholm and Krogerus (1998; 2003) measured DOP bioavailability from industrial, rural and urban wastewater plant effluents in Finland and reported 0-75\% bioavailability depending on the source and sampling time. Young et al. (1982) found all of the DOP in effluent from four municipal wastewater treatment plants to be available based on algal bioassays. Here, in triplicate bottle test analyses of the Maumee River sample, DOP was depleted in a stepwise fashion (Figure 4.1b) yielding $51 \pm 3 \%$ (C.V. $5 \%$ ) bioavailability. This result is consistent with literature indicating that DOP is partially available.

\subsubsection{Particulate Phosphorus}

DCDA Bioassay - particulate phosphorus has been shown to exhibit a high degree of variation in its bioavailability: $0-100 \%$ in wastewater, and $0-58 \%$ in rivers (Ekholm and Krogerus 2003; usings DCDA assays). Here, the bioavailability of the Maumee River PP sample was found to be $37 \pm 2 \%$ (C.V. 6\%) in triplicate DCDA bioassays (Figure 4.1c). Over the course of the bioassay, $1255 \pm 70 \mu \mathrm{gP} \cdot \mathrm{gDW}^{-1}$ was sequestered by the assay algae. The PP content of the sample declined from $3432 \pm 147$ $\mu \mathrm{gP} \cdot \mathrm{gDW}^{-1}$ to $1968 \pm 147 \mu \mathrm{gP} \cdot \mathrm{gDW}^{-1}$, a change $(\Delta \mathrm{P})$ of $1464 \pm 147 \mu \mathrm{gP} \cdot \mathrm{gDW}^{-1}$ equating to $43 \pm 4 \%$ bioavailability. The $\Delta \mathrm{P}$ result $\left(1464 \mu \mathrm{gP} \cdot \mathrm{gDW}^{-1}\right)$ serves as confirmation of the

algal assay estimate of bioavailability (1255 $\mu \mathrm{gP} \cdot \mathrm{gDW}^{-1}$; Figure 4.2). The $\Delta \mathrm{P}$ result showed good correlation with the DCDA result $\left(\mathrm{r}^{2}=0.88\right)$ for all five of the tributaries assayed. However, the slope of that relationship (1.36) indicates that the $\Delta \mathrm{P}$ approach 
tends to overestimate bioavailability (Figure 4.3) leading to the finding that the $\Delta \mathrm{P}$ result differed significantly $(\mathrm{p}<0.05)$ from the DCDA result for three of the five rivers assayed.

Chemical Assay - Fe/Al-P ( $\mathrm{NaOH}$ extractable $\mathrm{P})$, has been proposed as a surrogate for algal bioavailability (DePinto et al. 1981; Dorich et al., 1980, 1985; Fabre et al., 1996; Mayer et al., 1991; Sharpley et al., 1991). Here, the triplicate Maumee River samples had a Fe/Al-P concentration of $1448 \pm 48 \mu \mathrm{gP} \cdot \mathrm{gDW}^{-1}$, corresponding to a bioavailability of $41 \pm 1 \%$. This result compares well with that estimated by the DCDA bioassay $(37 \pm 2 \%)$ and $\Delta \mathrm{P}$ methods $(43 \pm 4 \%$; Figure 4.2$)$. However, the chemical assay approach did not perform equally well for samples from all rivers as discussed subsequently.

In summary, bottle test bioassays confirmed that SRP is readily and completely available in the Maumee River sample (but see Boström et al., 1988). The DOP fraction was shown to be partially (51\%) available in this source. The three approaches applied in determining PP bioavailability (DCDA assay, DCDA $\triangle \mathrm{P}$, and chemical fractionation) yielded similar results, averaging $37 \%$ for the DCDA method, $43 \%$ for the $\triangle \mathrm{P}$, and $41 \%$ for the Fe-Al P. The repeatability of the DCDA, $\triangle \mathrm{P}$ and $\mathrm{NaOH}$ methods were all acceptable with Coefficient of Variations (C.V.s) of 6\%, 9\%, and 2.5\% respectively. 


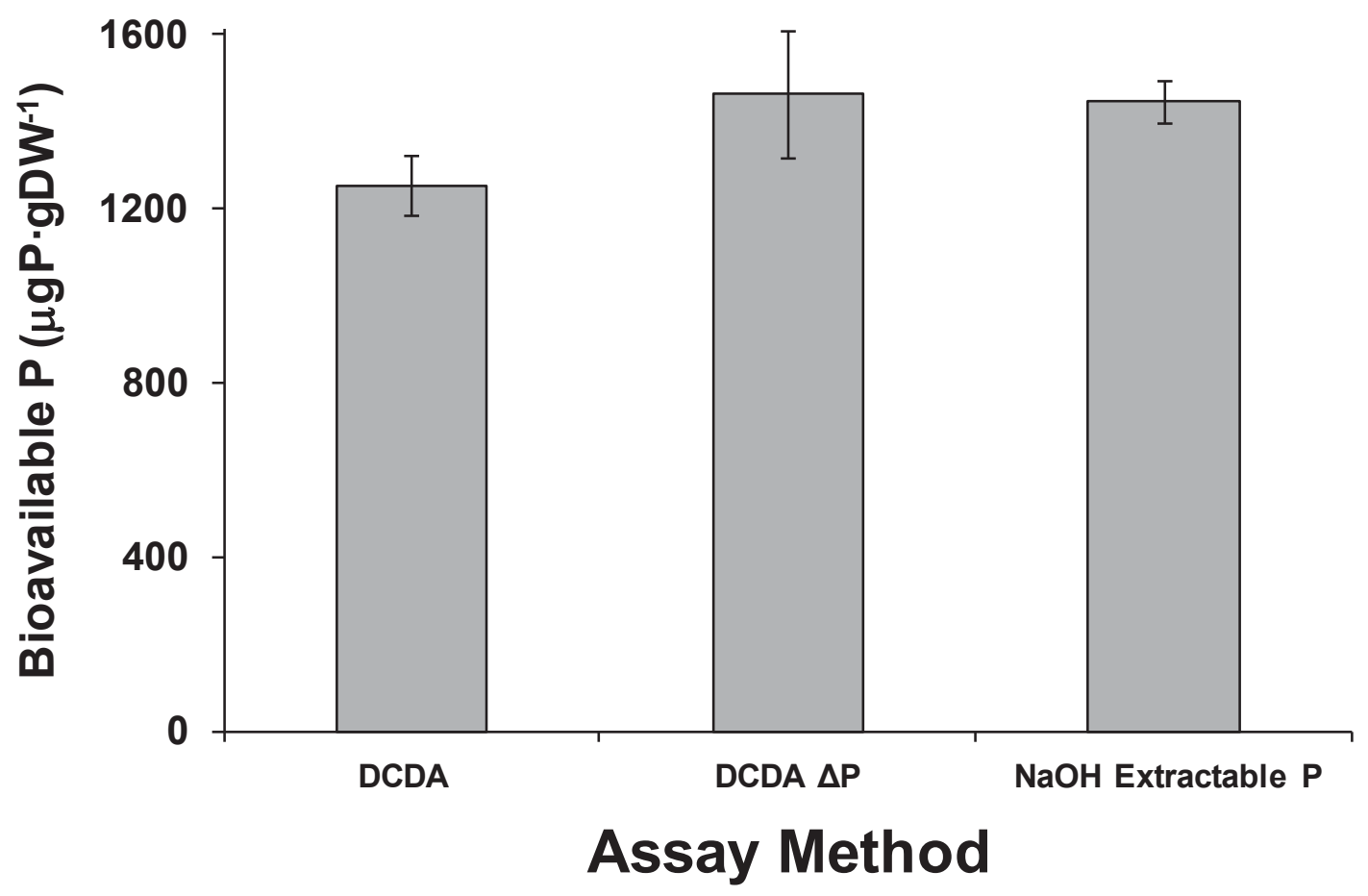

Figure 4.2 Bioavailability of the Maumee River sample (11/20/2010) as measured by the DCDA (directly and pre/post) and chemical fractionation techniques. 


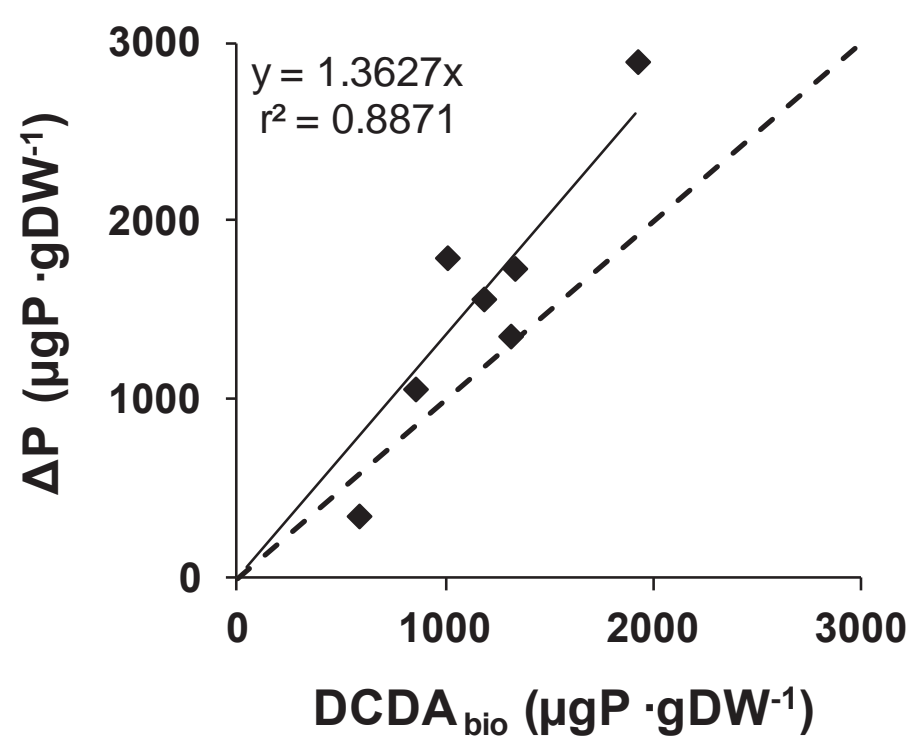

Figure 4.3 Relationship between the DCDA measured algal bioavailable concentration, and the change in sample P richness concentrations in DCDAs. (Dotted line is a 1:1 slope.) 


\subsection{Assay Results}

In all dissolved phase bioassays, SRP was $\sim 100 \%$ bioavailable (when considered within the analytical limits of the analysis), DOP averaged $67 \pm 19 \%$ bioavailable and PP averaged $36 \pm 19 \%$ bioavailable (Table 4.1 ). In a regression of the DOP concentration and the bioavailable DOP concentration a good relationship was found $\left(r^{2}=0.94\right.$; Figure 4.4). If a universal fraction bioavailable for DOP is found then it could be used for predicting DOP loads. The literature does not have conclusive answers for the bioavailability of DOP (Boström et al. 1988; see Section 4.1). The PP bioavailability results will be discussed in detail in subsequent sections. 
Table 4.1

Tributary $\mathrm{P}$ concentrations and results from all bioassays and fractionations

(a)

\begin{tabular}{|c|c|c|c|c|}
\hline Sample & \multicolumn{1}{c}{ Date } & TP $\mu \mathrm{gP} \cdot \mathrm{L}^{-1}$ & $\mathrm{TP}_{\text {bio }} \mu \mathrm{gP} \cdot \mathrm{L}^{-1}$ & $\mathrm{TP}_{\text {bio }}$ \\
\hline Maumee & $11 / 20 / 2010$ & 131 & 75 & 0.57 \\
\hline Fox & $11 / 28 / 2010$ & 48 & 37 & 0.76 \\
\hline Fox & $10 / 16 / 2011$ & - & - & - \\
\hline Sandusky & $11 / 20 / 2010$ & 40 & 30 & 0.76 \\
\hline Sandusky & $10 / 26 / 2011$ & 396 & 282 & 0.71 \\
\hline Cuyahoga & $11 / 20 / 2010$ & 85 & 48 & 0.56 \\
\hline Cuyahoga & $7 / 11 / 2011$ & 117 & 66 & 0.57 \\
\hline Saginaw & $11 / 20 / 2010$ & 49 & 39 & 0.80 \\
\hline
\end{tabular}

(b)

\begin{tabular}{|c|c|c|c|c|c|c|c|}
\hline \multirow[b]{2}{*}{ Sample } & \multirow[b]{2}{*}{ Date } & \\
\hline & & $\begin{array}{c}\mathrm{PP} \\
\mu \mathrm{gP} \cdot \mathrm{L}^{-1}\end{array}$ & $\begin{array}{c}\mathrm{PP}_{\text {bio }} \\
\mu \mathrm{gP} \cdot \mathrm{L}^{-1}\end{array}$ & $\begin{array}{c}\text { Richness } \\
\mu \mathrm{gP} \cdot \mathrm{gDW}^{-1}\end{array}$ & $\begin{array}{c}\mathrm{PP}_{\text {bio }} \\
\mu \mathrm{gP} \cdot \mathrm{gDW}^{-1}\end{array}$ & $\begin{array}{l}\text { PP } \\
f_{\text {bio }}\end{array}$ & $\begin{array}{c}\mathrm{k} \\
\mathrm{d}^{-1}\end{array}$ \\
\hline Maumee & 2010 & 70 & 26 & 3432 & 1255 & 0.37 & 0.10 \\
\hline Fox & 2010 & 12 & 8 & 4231 & 2887 & 0.68 & 0.07 \\
\hline Fox & 2011 & 45 & 17 & 3481 & 1323 & 0.38 & 0.13 \\
\hline Sandusky & 2010 & 15 & 7 & 1746 & 846 & 0.48 & 0.14 \\
\hline Sandusky & 2011 & 116 & 4 & 1501 & 46 & 0.03 & 0.07 \\
\hline Cuyahoga & 2010 & 44 & 11 & 2360 & 575 & 0.24 & 0.07 \\
\hline Cuyahoga & 2011 & 59 & 19 & 5803 & 1913 & 0.33 & 0.17 \\
\hline Saginaw & 2010 & 9 & 3 & 2726 & 999 & 0.37 & 0.11 \\
\hline
\end{tabular}


Table 4.1 (continued)

(c)

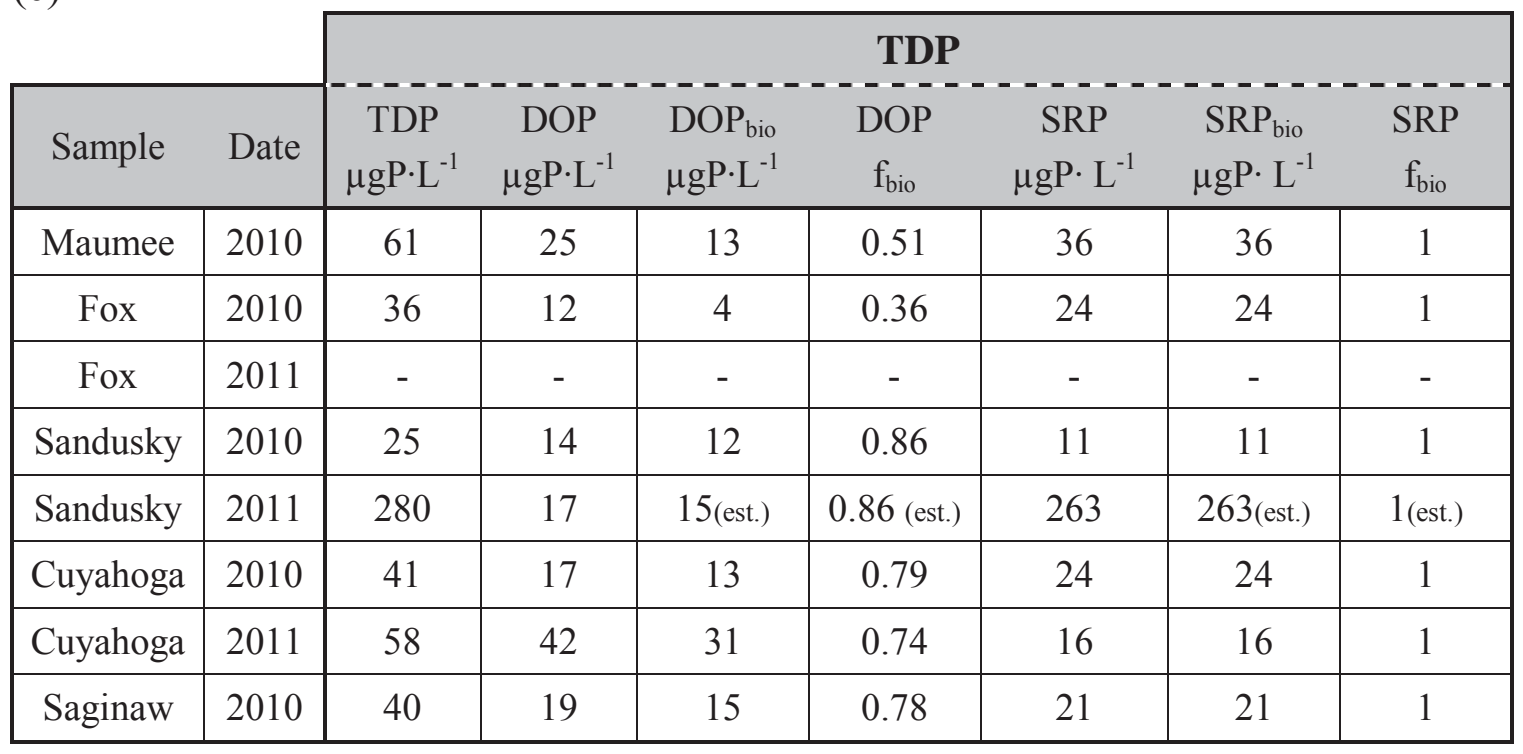

(d)

\begin{tabular}{|c|c|c|c|c|c|}
\cline { 3 - 6 } \multicolumn{1}{c|}{} & \multicolumn{4}{c|}{ PP fractions } \\
\hline Sample & Date & $\begin{array}{c}\text { Fe-Al } \\
\mathrm{ugP} \cdot \mathrm{gDW}^{-1}\end{array}$ & $\begin{array}{c}\text { Organic } \\
\mathrm{ugP} \cdot \mathrm{gDW}^{-1}\end{array}$ & $\begin{array}{c}\text { Ca-mineral } \\
\mathrm{ugP} \cdot \mathrm{gDW}^{-1}\end{array}$ & $\begin{array}{c}\text { Residual } \\
\mathrm{ugP} \cdot \mathrm{gDW}^{-1}\end{array}$ \\
\hline Maumee & 2010 & 1448 & 947 & 735 & 302 \\
\hline Fox & 2010 & 987 & 1845 & 659 & 740 \\
\hline Fox & 2011 & 976 & 1958 & 262 & 285 \\
\hline Sandusky & 2010 & 621 & 638 & 207 & 280 \\
\hline Sandusky & 2011 & 485 & 395 & 195 & 425 \\
\hline Cuyahoga & 2010 & 1376 & 179 & 466 & 339 \\
\hline Cuyahoga & 2011 & 2317 & 2614 & 457 & 415 \\
\hline Saginaw & 2010 & 1147 & 1004 & 283 & 292 \\
\hline
\end{tabular}




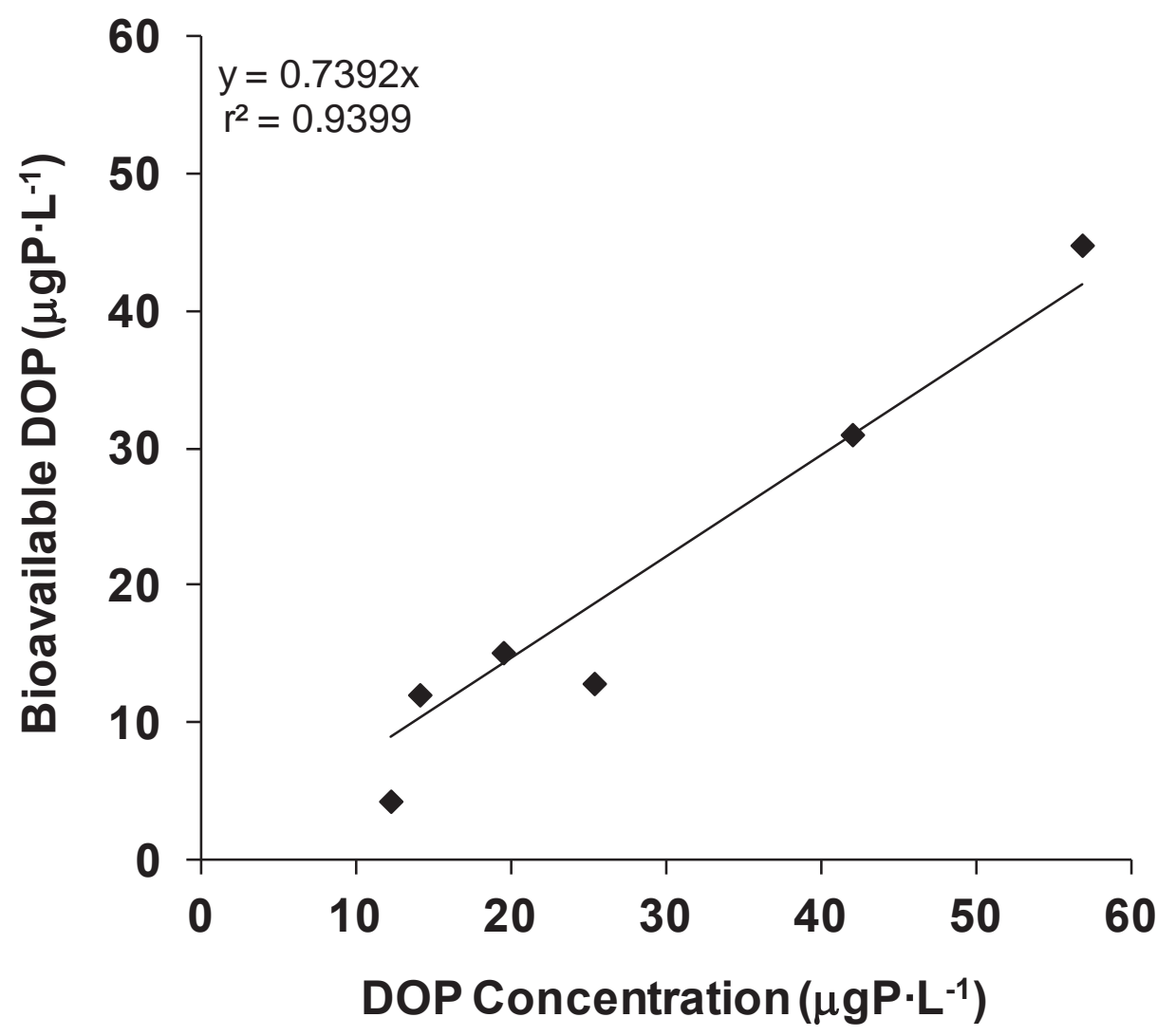

Figure 4.4 The DOP concentrations plotted with the bioavailable DOP concentrations. Fromm the slope the bioavailability is approximately $74 \%$. 


\subsection{Alternative Methods for Determining Bioavailable PP}

\subsubsection{Fe/Al-P: the $\mathrm{NaOH}$ extractable fraction}

Several authors have compared algal bioassay and sequential extraction methods and concluded that the Fe/Al-P ( $\mathrm{NaOH}$ extractable) fraction is a suitable surrogate for PP bioavailability (DePinto et al. 1981; Dorich et al., 1980; 1985; Fabre et al., 1996; Sharpley et al., 1991). In 1981, Young et al. (1985) conducted algal bioassays on 17 particulate P samples collected from tributaries to Lake Erie (Maumee, Sandusky, and Cuyahoga Rivers and Honey Creek). The bioavailability as determined by P uptake $(24 \pm 5 \%)$ did not differ significantly $(\mathrm{p}>0.05)$ from that estimated by the change in the various chemical fractions over the course of the assay $(23 \pm 9 \%)$. Further, Fe/Al-P accounted for $85 \pm 26 \%$ of the bioavailable P, suggesting that this fraction satisfactorily approximates P bioavailability. This study provides an appropriate frame of reference for the work presented here.

In the Lake Erie tributary algal bioassays conducted on samples collected in 2010 and 2011, the fraction bioavailable was higher (Maumee River, 37\% 0 ; Sandusky River, 48 $\pm 5 \%$; Cuyahoga River $33 \pm 1 \%$ ) and the contribution to bioavailable P from the Fe/Al-P fraction lower (Maumee River, 68\% \pm 6 ; Sandusky River, 50\%; Cuyahoga River 66\%) than those reported by Young et al. (1985; Figure 4.5). Additional contributions to the bioavailable $\mathrm{P}$ were derived from the Ca Mineral-P and organic-P fractions (Figure 4.5b), calling into question the use of Fe/Al-P as a sole surrogate for bioavailable P.

Agricultural best management practices implemented in the early 1980s greatly reduced erosion and thus the suspended solids content and load delivered by the Maumee 
(a)

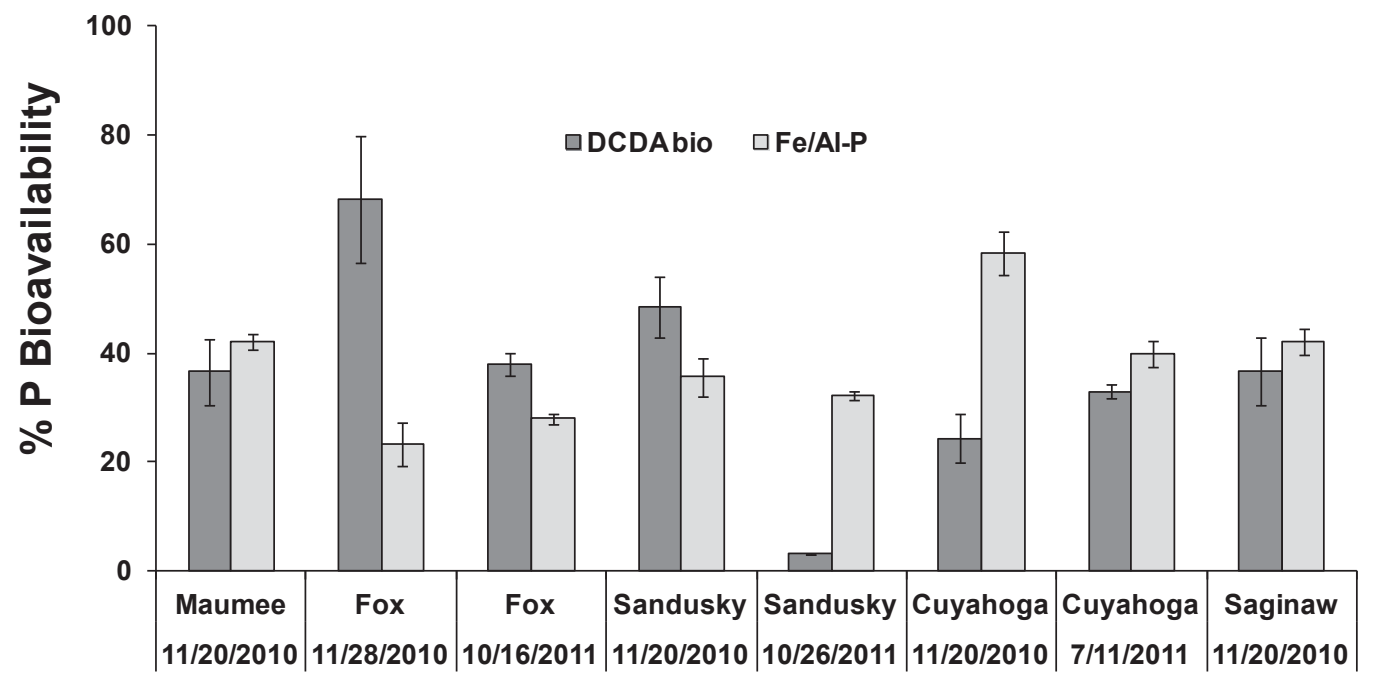

River and Sampling Date

(b)

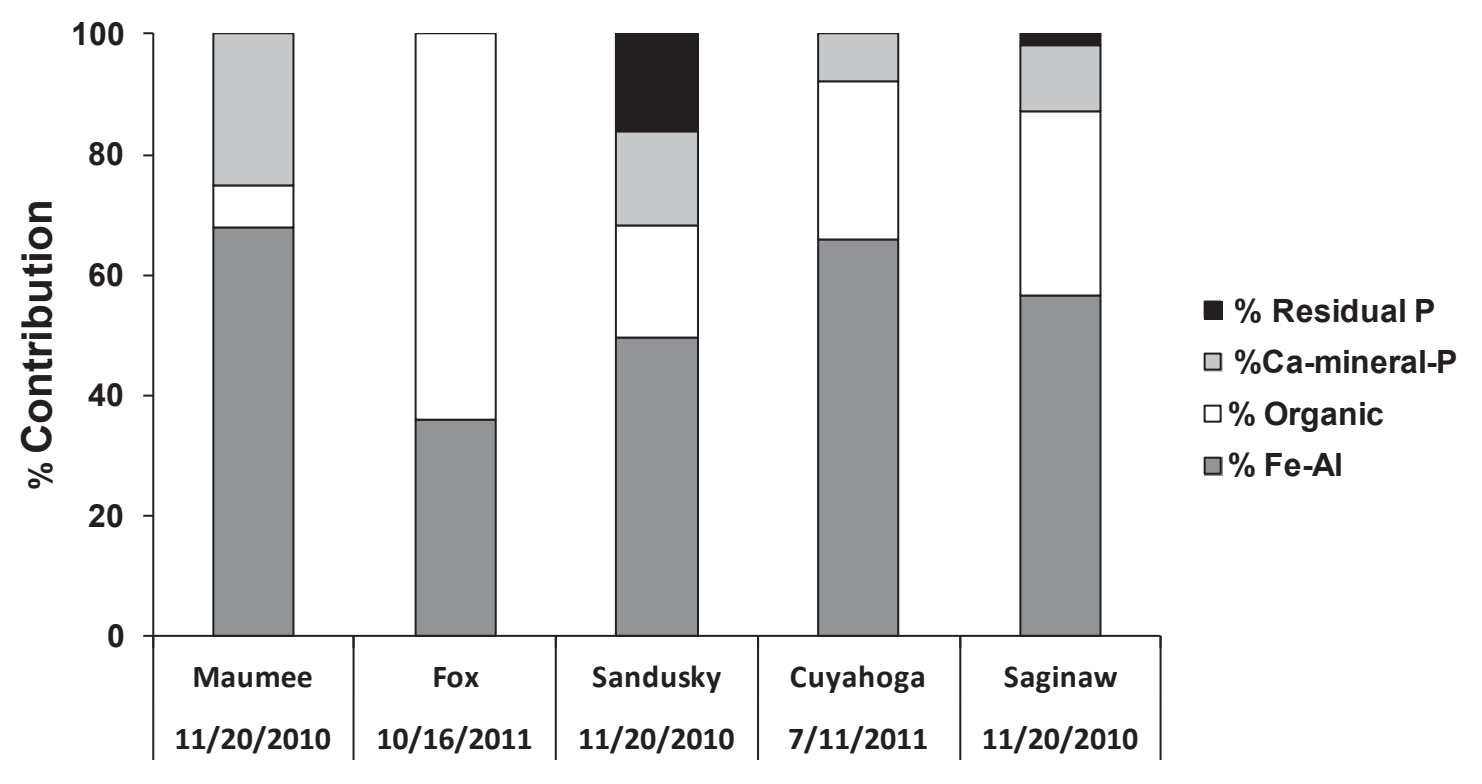

River and Sampling Date

Figure 4.5 (a) Bioavailability as measured by DCDA and $\mathrm{NaOH}$ extractable P methods. Error bars are standard deviation (b) Contributions (\%) of the chemically-defined phosphorus fractions to PP bioavailability. 
and Sandusky Rivers (Richards et al., 2008). These changes, together with improvements in wastewater treatment technologies over the three decades since the work of Young et al. (1985) may have altered the distribution of bioavailable particulate phosphorus among the various chemically-defined fractions, e.g. less contribution from the Fe/Al-P fraction, more from the organic-P fraction. The improved light climate associated with reduced suspended solids levels is potentially the basis for the high levels of algal biomass reported recently in the Maumee River (Bridgeman et al., 2011) and thus a greater contribution to bioavailable P from the organic-P fraction. Elevated levels of soluble reactive P (OhioEPA, 2010; Richards et al., 2010) are an unlikely cause for increased algal biomass as Maumee River concentrations have been extremely high for the past three decades (77 $\mu \mathrm{g} \cdot \mathrm{L}^{-1}$ in $1975-1985,57$ in $1990-1999$ and 87 in 2000-2010; based on concentration data from National Center for Water Quality Research at Heidelberg University).

Moving to locations beyond the study area of Young et al. (1985), Fe/Al-P contributed $36 \%$ of the bioavailable P in the Fox River and 57\% in the Saginaw River (Figure $4.5 \mathrm{~b}$ ), both markedly less than the $85 \%$ contribution determined for the Lake Erie tributaries (Young et al., 1985) leading to the promotion of Fe/Al-P as a surrogate for bioavailable $\mathrm{P}$. These results stand in contradiction to the long standing assumption that the Fe/Al-P fraction is representative of bioavailable P. Although Fe/Al-P continues to be used as a surrogate for bioavailable P (Baker, 2011; Hodson et al., 2004; Mayer et al., 1991; Zhou et al., 2001) and the utility of the approach has been examined for several inland waters (Auer et al., 1998; Sharpley et al., 1991; Dorich et al., 1985), its application 
has not been re-examined for Great Lakes tributaries since the pioneering work of Young et al. (1985).

\subsubsection{Correlating PP bioavailability, richness and chemical fractions}

A correlation between chemical fractionation measurements (e.g. Fe/Al-P) and bioavailability as determined by algal bioassays would provide a less resource intensive alternative to the DCDA method. However, it has been shown above that the Fe/Al-P analyte taken alone performs unsatisfactorily in this regard. Here, relationships between sediment $\mathrm{P}$ richness and bioavailable $\mathrm{P}$ (as determined through algal bioassays) and sediment $\mathrm{P}$ richness and sediment $\mathrm{P}$ fractions are examined.

Correlation of Bioavailable P with Sediment P Richness - this approach, requiring solids and PP measurements, is the least resource intensive of any of the means of characterizing P bioavailability. This relationship yields as its slope the fraction of the PP which is bioavailable. A strong relationship suggests a fraction bioavailable with universal application. Here, for samples from the five largest tributary $\mathrm{P}$ sources to the Great Lakes, the slope was 0.35 (35\% bioavailable; Figure 4.6a) with richness explaining $85 \%$ of the variability among samples $\left(r^{2}=0.85\right.$; Figure $\left.4.6 a\right)$. The relationship is essentially the same when restricted to Lake Erie tributaries only (Figure 4.6b) facilitating comparison to work done on those systems in the 1980s. The results obtained for Lake Erie tributaries by Young et al. $(1985 ; 24 \pm 2 \%$, mean $\pm 95 \%$ confidence interval, $\mathrm{n}=17)$ would not fall within the $95 \%$ confidence intervals for the estimated contemporary bioavailability of those tributaries (Figure $4.6 \mathrm{~b} ; 35 \pm 5 \%, \mathrm{n}=6$ ). This suggests that PP bioavailability may have increased for these locations over the last 30 years. Alternatively, differences in bioavailability may vary from month to month and 
(a)

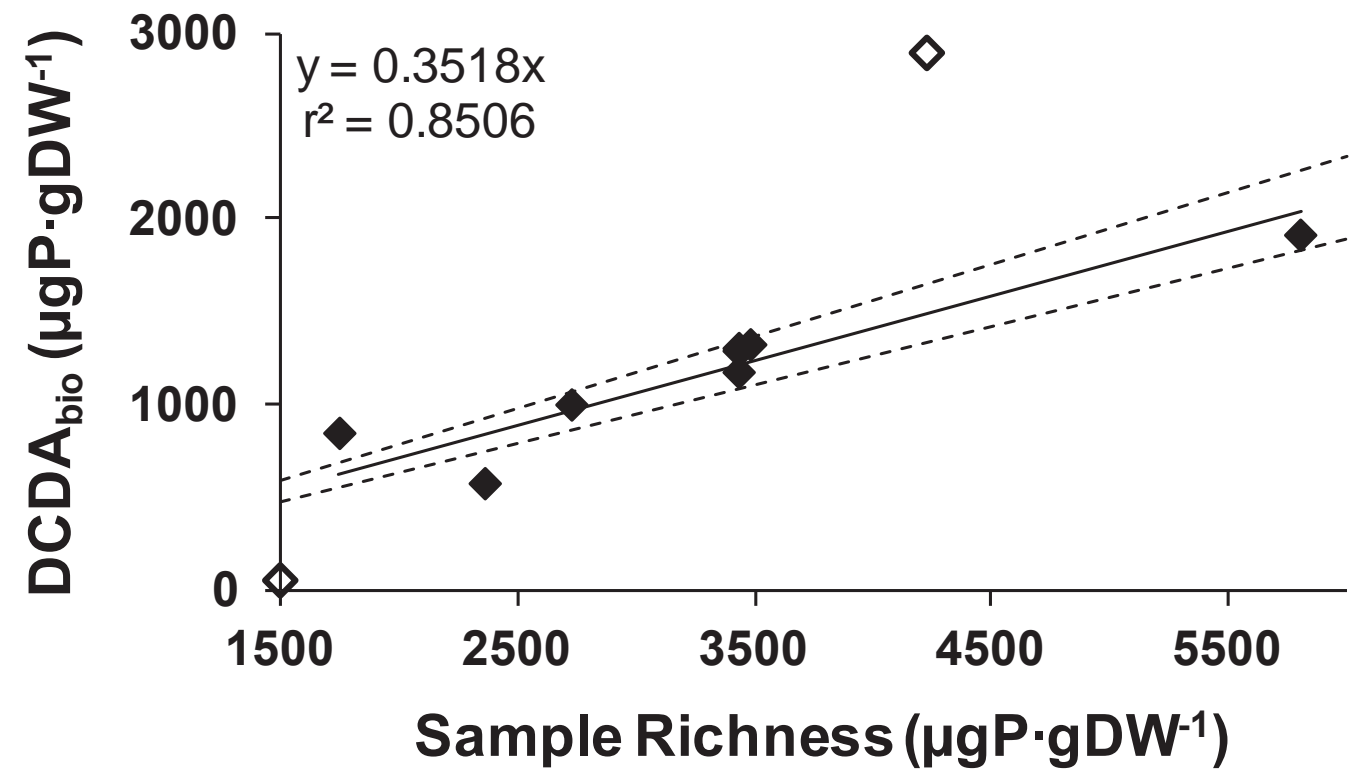

(b)

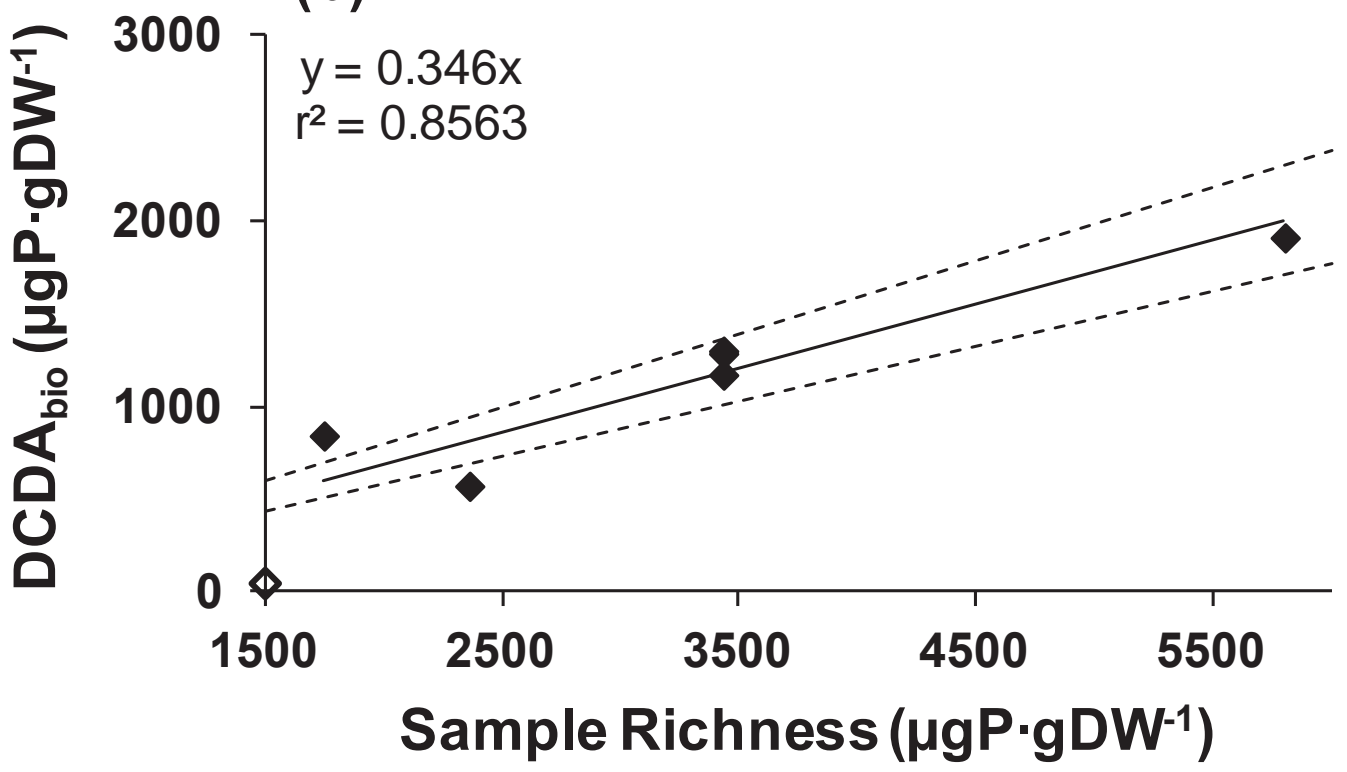

Figure 4.6 Relationship between sample P richness and DCDA measured bioavailable P. (a) All tributary data are included; the $95 \%$ confidence interval of the slope of the regression is between 0.32 and 0.39 (dotted lines). (b) Only Lake Erie Tributaries are included in the regression. The $95 \%$ confidence interval of the slope of the regression is between 0.30 and 0.40 . The Sandusky River sample collected on 10/26/2011 and the Fox River collected 11/28/2011 were not included in the regressions. 
could impart the differences observed between the 1980s and contemporary conditions (see Section 4.4).

Two points, not included in the regression, represented extreme cases meriting further consideration. The Sandusky River sample collected on 10/26/2011 had a PP bioavailability (3\%) well below the mean for all other tributaries (see Section 4.4, Table 4.1). This sample was collected during a wet weather event and it is hypothesized that an influx of rainwater would have promoted $\mathrm{P}$ desorption from suspended solids. At the other extreme, the Fox River sample collected on 11/28/2010 had a bioavailability (68\%) well above the mean (Section 4.4). The Fox River watershed is separated into upper and lower sub-watersheds by Lake Winnebago which acts as a sediment trap, removing inorganic particles from agricultural runoff (a rich source of Fe/Al-P). Bioavailable phosphorus is then converted to algal biomass (a rich source of organic-P) and thus a shift in the relative amounts of bioavailable P fractions. Thus, while there appears that there may be a value for the bioavailability coefficient $(\sim 35 \%)$ with some universal utility, the occurrence of outliers suggests that basin-specific information should be sought.

Correlation of Bioavailable $\mathrm{P}$ with Chemical Fractions - traditionally, bioavailable $\mathrm{P}$ has been associated with the Fe/Al-P and organic-P fractions (Boström et. al., 1988). In paired measurements of 40 samples collected from Lake Erie tributaries Young et al. (1985) determined that Fe/Al-P was well correlated with bioavailable P as measured using algal bioassays $\left(\mathrm{r}^{2}=0.803\right)$ and that $85 \%$ of the bioavailable $\mathrm{P}$ originated from the Fe/Al-P fraction. However, in a study of Onondaga Creek (New York) it was noted that the Fe/Al-P fraction contributed 54\% of the bioavailable-P (Nover, 2004) and, 
as described above, other chemically-defined fractions can contribute to bioavailability as well (Figure 4.5b). Here, each of the chemically-derived fractions will be examined singly and in combination for their efficacy in representing bioavailability.

In the current study both the Fe/Al-P and organic-P fractions were well correlated with bioavailable $\mathrm{P}\left(\mathrm{r}^{2}=0.81\right.$ and 0.82 , respectively, and $\mathrm{p}=0.006$ and 0.002 , respectively) and a multiple regression using both fractions yielded the strongest correlation $\left(\mathrm{r}^{2}=0.83\right.$; Fe-Al-P Coefficient $=0.51$, Organic-P Coefficient $=0.38$; Figure 4.7). Although bioavailable $P$ increased with increases in both Ca-mineral $P$ and residual $\mathrm{P}$, the response was modest and the correlation poor and these were not included in the multiple regression analysis. This would be expected as these fractions are traditionally assumed to yield little bioavailable P (Boström et. al., 1988; Young et. al., 1985). While there is good evidence for universal application of these regressions, samples from some sites, on some dates did not fit the model well (Fox 2010 all, Sandusky 2011 all, and Cuyahoga 2010 was not included in the Fe/Al-P regression). This may be a result of siteto-site differences in the nature of the particulate matter or to seasonality in PP bioavailability. These phenomena need to be addressed before bioavailability surrogates can be reliably applied.

\subsection{Geospatiotemporal Variability}

Despite the fact that bioavailability has been shown to be well correlated with: PP-richness, Fe/Al-P and organic-P, striking variability in bioavailability is observed both geospatially among tributaries and temporally within tributaries. The occurrence of outliers suggests that the spatiotemporal variability of these rivers should be studied 
(a)

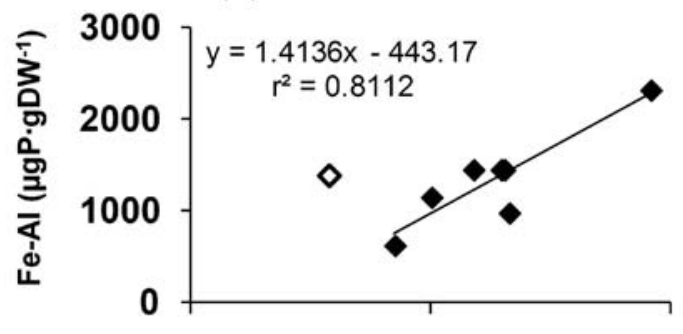

(c)

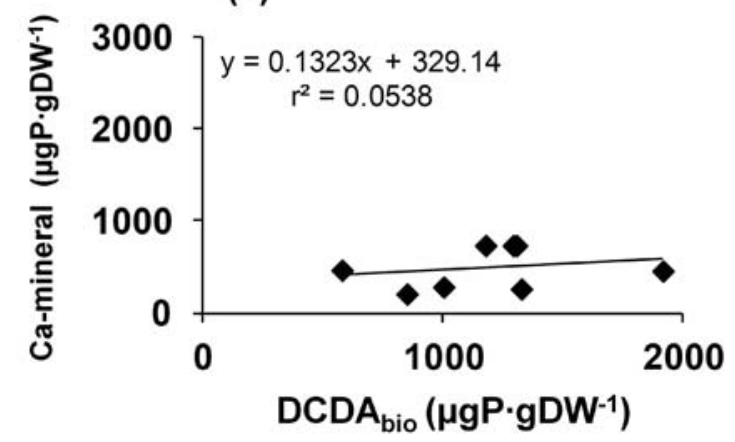

(b)

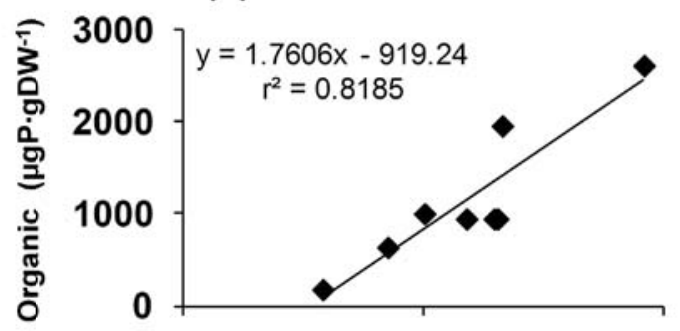

(d)

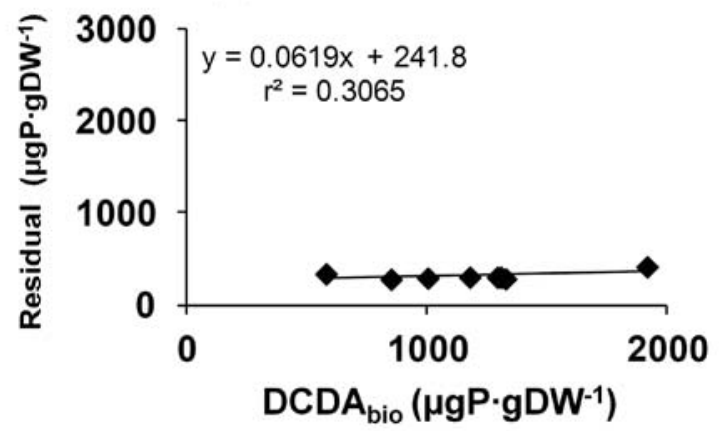

(e)

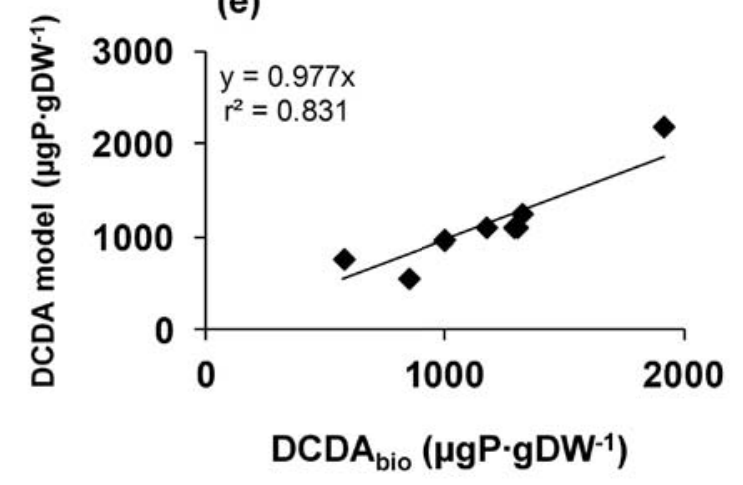

Figure 4.7 (a-d) Regressions of DCDA bioavailability and fractions (Cuyahoga $11 / 20 / 2010$ was not included in the Fe/Al-P regression it was an outlier) and (e) multiple regression of the Fe/Al-P (Coefficient $=0.51$ ) and Organic-P (Coefficient $=0.38$ ) fractions and DCDA bioavailability (Ca-mineral-P and Residual-P were not included in the regression). 
further.

An example of temporal variation within a single tributary is provided by the Sandusky River data. Here, sampling represented two different flow regimes: in 2010, during dry weather $(\mathrm{Q}=124 \mathrm{cfs} ; 67 \%$ exceedance probability 89 year record), PP bioavailability was $49 \%$ and in 2011 , during wet weather at the tail end of a storm surge $(\mathrm{Q}=1690 \mathrm{cfs} ; 16 \%$ exceedance probability; peak of storm $\mathrm{Q}=12000 \mathrm{cfs} 0.9 \%$ exceedance probability) it was 3\% (Figure 3.2 e and f; Figure 4.5a). Findings were similar for assays of tributaries to Onondaga Lake (New York), where PP bioavailability was 22-52\% under low flow conditions (fall; Onondaga Creek Q $=47$ cfs, 92\% exceedance probability; Effler et al., 2002), and negligible during high flow conditions $(4 / 13 / 2011 \mathrm{Q}=404 \mathrm{cfs}, 8.3 \%$ exceedance probability, $11 / 28 / 2011 \mathrm{Q}=205 \mathrm{cfs} 29 \%$ exceedance probability, all flow data from Onondaga Creek). Also, PP was twice as bioavailable under dry-weather conditions than during wet weather in the major tributary to Cannonsville Reservoir (New York; Auer et al., 1998). Differences in the bioavailability of the Sandusky River samples occurred despite the fact that their Fe/Al-P fraction concentrations were similar. It is hypothesized that the dilution during high flow events causes desorption of bioavailable phosphorus from particulate matter, calling into question the value of Fe/Al-P as a surrogate under all flow regimes.

Watersheds differ geologically and in the nature of their anthropogenic sources of particulate matter; thus surrogate methods for characterizing bioavailability may not respond consistently. This feature is illustrated in samples collected from the Fox River where one sample (11/28/2010) exhibited the highest bioavailability (68\%) of any sample collected in this study, while another (10/16/2011) had a bioavailability (38\%) 
comparable to that of all other sites. Although this clearly reflects an intrasystem variation, the difference cannot be ascribed to flow conditions (i.e. desorption) as flows were similar and comparable to long term Fox River averages in both cases. A striking difference exists in the ratio of Fe/Al-P to organic-P in the Fox River (0.52) versus the other tributaries (2.44) pointing to a significant enrichment in organic-P in the Fox River. As discussed previously, this difference reflects the 'sediment trap - algae incubator' role of Lake Winnebago upstream. Thus, for the Fox River, bioavailability is expected to vary with the organic-P contribution (nature, quantity) both within the system seasonally and in comparison with other systems.

\subsection{Toward an Approach}

As discussed previously, a correlation between chemical analytes and PP bioavailability as determined by algal bioassays would provide a less resource intensive alternative to the DCDA method. If a universal (i.e. widely applicable) relationship is found between bioavailability and a surrogate analyte then the bioavailable P load could be easily estimated based on the surrogate concentration and tributary flow. The two regression relationships with the highest correlation, developed for all five rivers, were Prichness with bioavailable $\mathrm{P}\left(\mathrm{r}^{2}=0.85\right.$; Figure 4.6) and a multiple regression of the Fe/Al-P and organic-P fractions with bioavailable $\mathrm{P}\left(\mathrm{r}^{2}=0.83\right.$; Figure $\left.4.7 \mathrm{e}\right)$. However, as discussed in previous sections, there were outliers in all regressions suggesting that geospatiotemporal variability in bioavailability must be accounted for. Geospatially, watershed specific relationships can be developed where a universal regression doesn't apply (e.g., Fox River). Similarly, seasonal studies should be performed to establish a relationship within a watershed. 
Particulate phosphorus is, however, only one aspect of the bioavailability narrative; other phosphorus forms (soluble reactive and dissolved organic) might be equal or greater importance. Measurements of the bioavailability of SRP, DOP and PP along with their concentration data allow a comparison of the contribution of each within the context of TP and bioavailable P (Figure 4.8). For example, in the Maumee River sample collected in $2010 \mathrm{SRP}$, DOP and PP contributed 29, 20 and 51\% of the TP $\left(125 \mu \mathrm{g} \cdot \mathrm{L}^{-1}\right.$; Figure 4.9). However, on the basis of bioavailability, SRP, DOP and PP contributed 49, 18 and $33 \%$ (Figure 4.9). Note that the contribution of SRP becomes more important when the fraction bioavailable is accounted for. The Cuyahoga River sample collected in 2010 revealed similar results: PP accounted for $49 \%$ of the TP but only $20 \%$ of the bioavailable P and SRP contributed $30 \%$ of the TP and $52 \%$ of the bioavailable P. For the 2011 Cuyahoga River and 2010 Sandusky samples, DOP had more significance with respect to bioavailability. In the Fox and Saginaw samples of 2010 SRP dominated the P concentrations in the rivers, and they were also the largest portion of the bioavailable P. In this manner, water quality managers are provided with the information necessary to target P sources based on bioavailability.

\subsection{A Proposed Monitoring Program}

Historically, monitoring programs have focused solely on determination of total phosphorus loads. This focus tends to overestimate the amount of phosphorus contributing to eutrophication (i.e. bioavailable P) and over-regulation may result by targeting constituents with little bioavailability. 


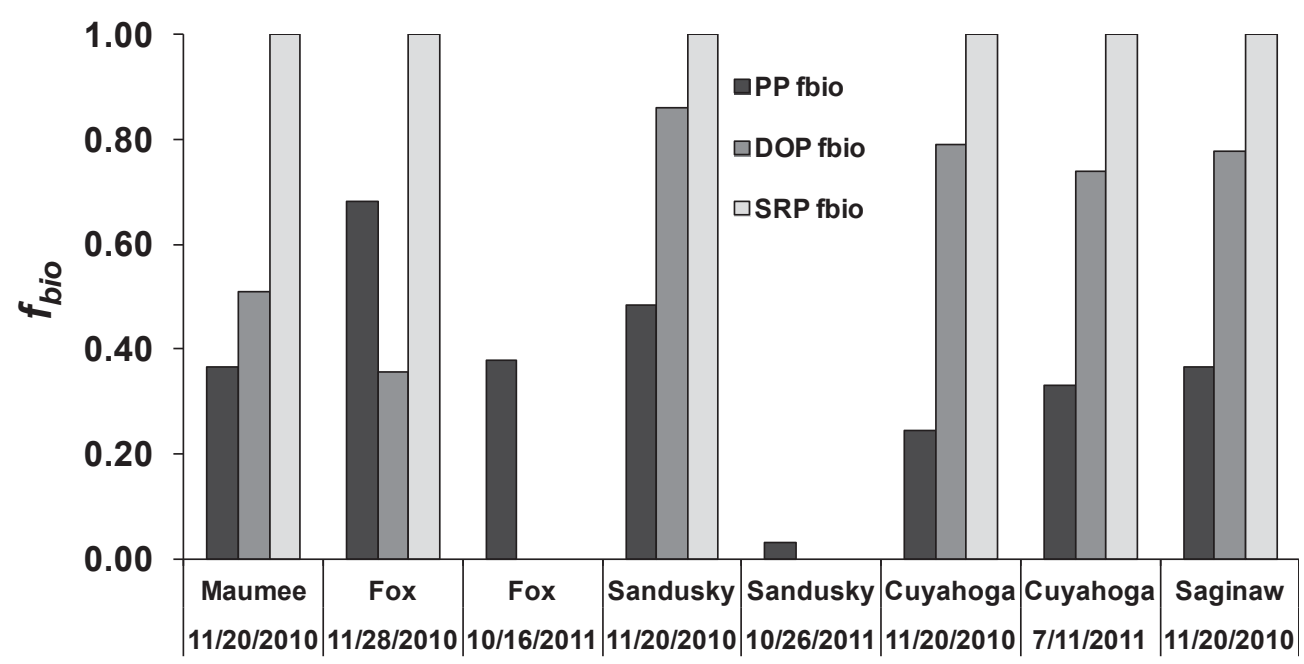

River and Sampling Date

Figure 4.8 The fraction bioavailable $\left(f_{\text {bio }}\right)$ of all samples (two samples did not have dissolved bioassays) 


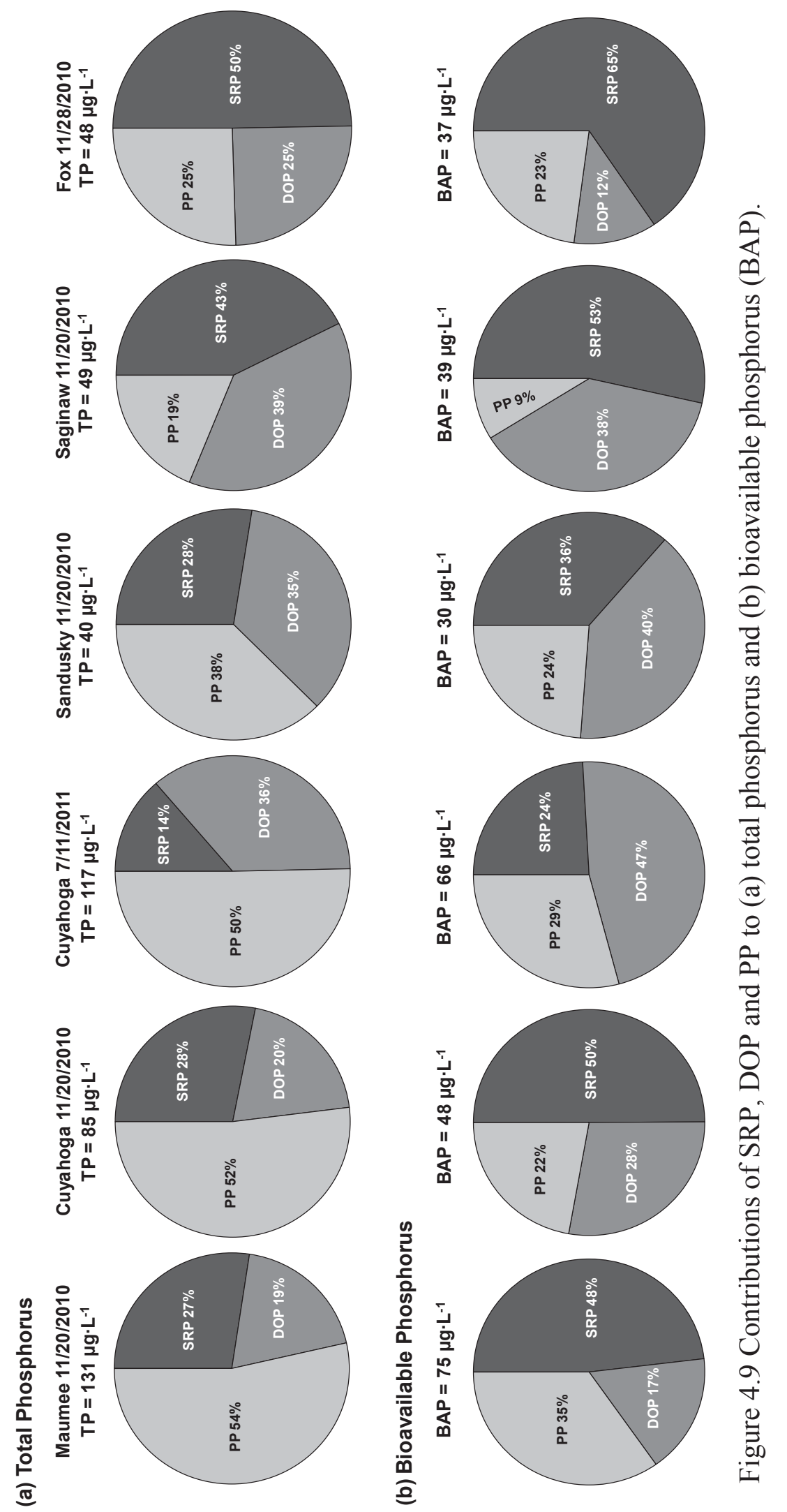


The first priority of a new monitoring program should be characterization of the soluble reactive phosphorus loading, the most bioavailable P form. The next step would be to determine DOP bioavailability using algal bioassays; the need for consideration of variation in time and space should be recognized. Finally, paired particulate phase bioassays and chemical fractionations would be employed to verify or develop the utility of chemical surrogates. These studies would be done in all seasons and in dry and wet weather conditions on a system by system basis in order to characterize the seasonality and variability of $\mathrm{P}$ bioavailability.

Once relationships between algal bioavailability and chemical surrogates (either chemical fractions or $\mathrm{P}$ richness) are developed and tested with respect to season and/or weather events, these surrogates can be incorporated in routine monitoring programs supporting estimation of bioavailable P loads. Every 7-10 years, follow up bioassay studies should be performed to verify the continued utility of chemical surrogates as agricultural practices and human populations change within the watershed. 


\section{Summary and Conclusions}

The bioavailability of phosphorus can be repeatably measured with algal bioassays and these methods would be recommended for quantifying algal availability. Algal bioavailability can also be estimated with chemical fractions and sample richness if reliable relationships between algal bioavailability and chemical surrogates are established (i.e. through bioassays). These chemical estimates are not always reliable and the frequency of outliers also needs to be addressed in future studies. The impact of PP and DOP is much lower as a portion of the phosphorus load when the bioavailability is known because these constituents were only partially bioavailable (36 $\pm 19 \%$ and $67 \pm 19 \%$ respectively). The contribution of SRP is always larger because it is $100 \%$ bioavailable.

A monitoring program could implement these methods, and target the largest bioavailable loads. In a proposed monitoring program: the SRP contribution should be quantified first, then the bioavailability and contributions of PP (estimated with algal bioassays and chemical surrogates) and DOP (estimated with algal bioassays). Quantification of bioavailability would allow for better characterization of the eutrophication issues in the Great Lakes. 


\section{References}

APHA, American Public Health Association, 2005. Standard Methods for the Examination of Water and Wastewater in: Franson, M. A. H. (Ed.), 21 ed. American Public Health Association, American Water Works Association, Water Environment Federation Washington, DC.

Auer, M. T., Tomasoski, K. A., Babiera, M. J., Needham, M. L., Effler, S. W., Owens, E. M. et al. 1998. Phosphorus Bioavailability and P-Cycling in Cannonsville Reservoir. Journal of Lake and Reservoir Management. 14, 278-289.

Auer, M. T., Tomlinson, L. M., Higgins, S. N., Malkin, S. Y., Howell, E. T., and Bootsma, H. A. 2010. Great Lakes Cladophora in the 21st century: same algaedifferent ecosystem. Journal of Great Lakes Research. 36, 248-255.

Baker, D. B., 2011. The Sources and Transport of Bioavailable Phosphorus to Lake Erie Final Report: Part 1 Trends in Bioavailable Phosphorus Loading at River Monitoring Stations. National Center for Water Quality Research Heidelberg University, Tiffin, p. 30.

Boström, B., Persson, G., and Broberg, B. 1988. Bioavailability of different phosphorus forms in freshwater systems. Hydrobiologia. 170, 133-155.

Bridgeman, T. B., Chaffin, J. D., Kane, D. D., Conroy, J. D., Panek, S. E., and Armenio, P. M. 2012. From River to Lake: Phosphorus partitioning and algal community compositional changes in Western Lake Erie. Journal of Great Lakes Research. 38, 90-97.

Connors, S. D., Auer, M. T., and Effler, S. W. 1996. Phosphorus Pools, Alkaline Phosphatase Activity, and Phosphorus Limitation in Hypereutrophic Onondaga Lake. Lake and Reservoir Management. 12, 47-57.

DePinto, J. V. 1982. An Experimental Apparatus for Evaluating Kinetics of Available Phosphorus Release from Aquatic Particulates. Water Research. 16, 1065-1070.

DePinto, J. V., Lam, D., Auer, M., Burns, N., Chapra, S., Charlton, M. et al., 2006. Examination of the status of the goals of Annex 3 of the Great Lakes Water Quality Agreement. Report of the Annex 3 Model Review Sub-Group to the GLWQA Review Working Group D-Nutrients. 
DePinto, J. V., Young, T. C., and Martin, S. C. 1981. Algal-avaibable phosphorus in Suspended Sediments from Lower Great Lakes Tributaries. Journal of Great Lakes Research. 7, 311-325.

Dorich, R. A., Nelson, D. W., and Sommers, L. E. 1980. Algal Availability of Sediment Phosphorus in Drainage Water of Black Creek Watershed. Journal of Environmental Quality. 9, 557-563.

Dorich, R. A., Nelson, D. W., and Sommers, L. E. 1985. Estimating Algal Available Phosphorus in Suspended Sediments by Chemical Extraction. Journal of Environmental Quality. 14, 400-405.

Effler, S. W., Auer, M., Peng, F., Perkins, M., O'Donnell, S. M., Matthews, D. A. et al. 2012. Factors Diminishing the Effectiveness of Phosphorus Loading from Municipal Effluent: Critical Information for TMDL Analyses. Water Environment Research. In Press.

Effler, S. W., O'Donnell, S. M., Matthews, D. A., Matthews, C. M., O'Donnell, D. M., Auer, M. T. et al. 2002. Limnological and loading information and a phosphorus total maximum daily load (TMDL) analysis for Onondaga Lake. Lake and Reservoir Management. 18, 87-108.

Ekholm, P. 1994. Bioavailability of phosphorus in agriculturally loaded rivers in southern Finland. Hydrobiologia. 287, 197-194.

Ekholm, P., Jouttijarvi, T., Priha, M., Mannu, R., and Nurmesniemi, H. 2007. Determining algal-available phosphorus in pulp and paper mill effluents: Algal assays vs routine phosphorus analyses. Environmental Pollution. 145, 715-722.

Ekholm, P., and Krogerus, K. 1998. Bioavailability of phosphorus in purified municipal wastewaters. Water Research. 32, 343-351.

Ekholm, P., and Krogerus, K. 2003. Determining algal-available phosphorus of differing origin: routine phosphorus analyses versus algal assays. Hydrobiologia. 492, 2942.

Ekholm, P., Rita, H., Pitkänen, H., and Rantanen, P. 2009. Algal-available Phosphorus Entering the Gulf of Finland as Estimated by Algal Assays and Chemical Analyses. Journal of Environmental Quality. 38, 2322-2333.

Evans, M. A., Fahnenstiel, G., and Scavia, D. 2011. Incidental Oligotrophication of North American Great Lakes. Environmental Science \& Technology. 45, 3297-3303. 
Fabre, A., Qotbi, A., Dauta, A., and Baldy, V. 1996. Relation between algal available phosphate in the sediments of the River Garonne and chemically-determined phosphate fractions. Hydrobiologia. 335, 43-48.

Fry, J. A., Xian, G., Jin, S., Dewitz, J. A., Homer, C. G., Yang, L. et al. 2006. Completion of the 2006 National Land Cover Database for the Conterminous United States. Photogrammetric Engineering \& Remote Sensing. 77, 858-864.

Hecky, R. E., Smith, R. E. H., Barton, D. R., Guildford, S. J., Taylor, W. D., Charlton, M. N. et al. 2004. The nearshore phosphorus shunt: a consequence of ecosystem engineering by dreissenids in the Laurentian Great Lakes. Canadian Journal of Fisheries and Aquatic Sciences. 61, 1285-1293.

Hodson, A., Mumford, P., and Lister, D. 2004. Suspended sediment and phosphorus in proglacial rivers:bioavailability and potential impact upon the $\mathrm{P}$ status of icemarginal receiving waters. Hydological Processes. 18, 2409-2422.

IJC, International Joint Commission, 1978. Great Lakes Water Quality Agreement, with Annexes and Terms of Reference between the United States and Canada signed at Ottawa November 22, 1978 and Phosphorus Load Reduction Supplement signed October 16, 1983, 1978 ed.

Mayer, T., Kuntz, K. W., and Moller, A. 1991. Total and Bioavailable Particulate Phosphorus Loads from the Niagara River in 1987 and 1988. Journal of Great Lakes Research. 17, 446-453.

Miller, W. E., Green, J. C., and Shiroyama, T., 1978. The Selenastrum Capricornutum Printz Algal Assay Bottle Test, Experimental Design, Application, and Data Interpretation Protocal. US EPA, Corvallis, Oregon.

Nover, D., 2004. Management Applications and Measurement of Bioavailable Particulate Phosphorus, Civil and Environmental Engineering. Michigan Technological University, Houghton.

OhioEPA, Ohio Evironmental Protection Agency, 2010. Ohio Lake Erie Phosphorus Task Force Final Report.

Penn, M. R., and Auer, M. T. 1997. Seasonal variability in phosphorus speciation and deposition in a calcareous, eutrophic lake. Marine Geology. 139, 47-59. 
Penn, M. R., Auer, M. T., VanOrman, E. L., and Karienek, J. J. 1995. Phosphorus diagenesis in lake sediments: investigation using fracrionation techniques. Marine and Freshwater Research. 46, 89-99.

Persson, G. 2001. Phosphorus in Tributaries to Lake Mälaren, Sweden: Analytical Fractions, Anthropogenic Contribution and Bioavailability. AMBIO: A Journal of the Human Environment. 30, 486-495.

Richards, R. P., Baker, D. B., Crumrine, J. P., Kramer, J. W., Ewing, D. E., and Merryfield, B. J. 2008. Thirty-Year Trends in Suspended Sediment in Seven Lake Erie Tributaries. Journal of Environmental Quality. 37, 1894-1908.

Richards, R. P., Baker, D. B., Crumrine, J. P., and Stearns, A. M. 2010. Unusually large loads in 2007 from the Maumee and Sandusky Rivers, tributaries to Lake Erie. Journal of Soil and Water Conservation. 65, 450-462.

Robinson, J. S., Sharpley, A. N., and Smith, S. J. 1994. Development of a method to determine bioavailable phosphorus loss in agricultural runoff. Agriculture, Ecosystems and Environment. 47, 287-297.

Sharpley, A. N., Troeger, W. W., and Smith, S. J. 1991. The Measurement of Bioavailable Phosphorus in Agricultural Runoff. Journal of Environmental Quality. 20, 235-238.

Uusitalo, R., and Ekholm, P. 2003. Phosphorus in Runoff Assessed by Anion Exchange Resin Extraction and an Algal Assay. Journal of Environmental Quality. 32, 633641.

Young, T. C., DePinto, J. V., Flint, S. E., Switzenbaum, M. S., and Edzwald, J. K. 1982. Algal Availability of Phosphorus in Municipal Wastewater. Water Pollution Control Federation. 54, 1505-1516.

Young, T. C., DePinto, J. V., Martin, S. C., and Bonner, J. S. 1985. Algal-Available Particulate Phosphorus in the Great Lakes Basin. Journal of Great Lakes Research. 11, 434-446.

Zhou, Q., Gibson, C. E., and Zhu, Y. 2001. Evaluation of phosphorus bioavailability in sediments of three contrasting lakes in China and the UK. Chemosphere. 42, 221225. 